九州大学学術情報リポジトリ

Kyushu University Institutional Repository

Systqmatics and evolution of weevils of $t$, he genus Bagous Germar (Coleoptera:

Curculionidae), III. Phylogenetic analysis of the species known from Japan

Askevold, Ingolf S.

Entomological Laboratory, Faculty of Agriculture, Kyushu University

O'Brien, Charles W.

Entomological Laboratory, Faculty of Agriculture, Kyushu University

Morimoto, Katsura

Entomological Laboratory, Faculty of Agriculture, Kyushu University

https://doi.org/10.5109/2571

出版情報: ESAKIA. 34，pp.75-129，1994-03-24. Entomological Laboratory，Faculty of Agriculture， Kyushu University

バージョン：

権利関係 : 


\title{
Systematics and evolution of weevils of the genus Bagous Germar (Coleoptera: Curculionidae), III. Phylogenetic analysis of the species known from Japan'
}

\author{
Ingolf S. ASKEVOLD, Charles W. O'BRIEN \\ Entomology - Biological Control, Florida A \& M University, \\ Tallahassee, FL 32307 \\ and \\ Katsura MORIMOTO \\ Entomological Laboratory, Faculty of Agriculture, Kyushu \\ University, Fukuoka, 812 Japan
}

\begin{abstract}
Phylogenetic analysis of members of Bagous known to occur in Japan was performed to produce an hypothesis about the phylogenetic relationships of the 17 species. Both manual and computer-aided reconstructions were performed. On the basis of this analysis, eight species groups were recognized, the $B$. pygmaeus group (including B. minor and B. pygmaeodes), the B. bipunctatus group (including B. kagiashi, B. ryukyuensis, B. occultus, B. spiculatus, B. bipunctatus and B. subcordatus), the B. fractus group (including B. fractus), the B. frit group (including B. fritodes), the B. transversus group (including B. young $i$ ), the $B$. rotundatus group (including $B$. rotundatus), the B. buckinghami group (including B. buckinghami), and the B. proprius group (including B. proprius).

The hypothesis of phylogeny compared well with a previous analysis of Australian species of the genus and integrated well with it. Combining Australian and Japanese species in the analysis did not significantly alter topology of branches. Thus, relationships of species and groups of species as determined independently for species of each of these geographically separated faunas is corroborated. This concordance indicates that phylogenetic analysis based on a subset of members of a taxon, while excluding the majority of its members, can
\end{abstract}

1 Contribution from the Entomological Laboratory, Faculty of Agriculture, Kyushu University, Fukuoka (Ser. 4, No. 58). 
be a valuable tool in development of a classification.

Several species are known only from females and therefore cannot be confidently assigned to species groups: B. lewisi, B. subvittatus, and $B$. tuberculosus. On the basis 'of characters used for analysis, placement in relation to known species is equivocal because these species share homoplastic characters with several other species which are not closely related to each other. These species are placed in an uncertain position among Japanese Bagous. Also known only from females, B. subcordatus has genitalia rather similar to certain species in the B. bipunctatus group, and is tentatively assigned to that group as most closely related to B. bipunctatus. Species known only from male specimens (B. occultus and B. rotundatus) can be confidently placed phylogenetically because many of the important, phylogenetically useful characters are found in male genitalia.

The Japanese Bagous constitute a diverse assemblage of species whose closest relatives occur in Southeast Asia, North America, or in the Palearctic Region. Several species groups represented in Japan are monobasic, but we fully expect that each is closely related to other, non-Japanese species with which we are unfamiliar at this time.

Computer analysis using PAUP agrees closely with manual reconstruction of relationships; differences are due to the more conservative, compromising hypothesis presented. Manual reconstructions tend to be most similar to $50 \%$ majority-rule consensus trees.

\section{CONTENTS.}

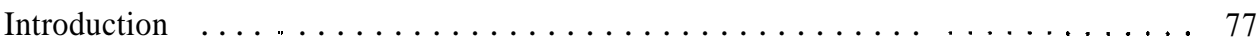

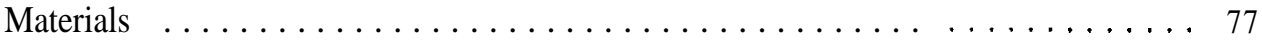

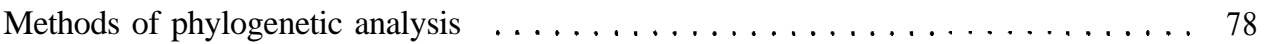

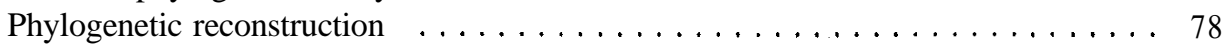

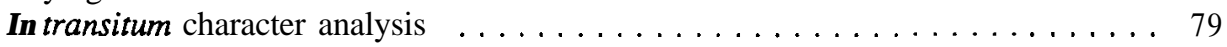

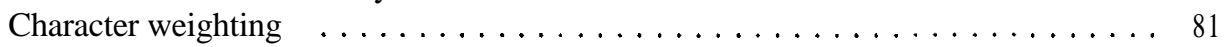

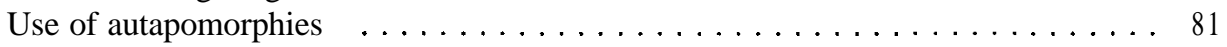

Treatment of taxa known only from one sex $\ldots \ldots \ldots \ldots \ldots \ldots \ldots$

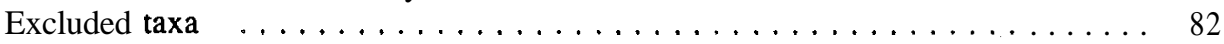

Rationale for geographically restricted study and analysis $\ldots \ldots \ldots \ldots \ldots 2$

Recognition of species groups $\ldots \ldots \ldots \ldots \ldots \ldots \ldots \ldots \ldots \ldots \ldots$

Characters Used in Phylogenetic Reconstruction . . . . . . . . . . . . . . . 84

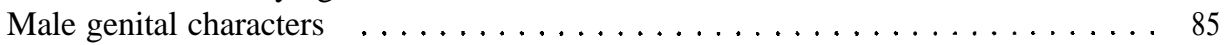

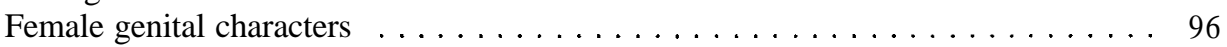

External characters $\ldots \ldots \ldots \ldots \ldots \ldots \ldots \ldots \ldots \ldots \ldots \ldots \ldots \ldots \ldots$

Results and Discussion

Manual reconstruction of relationships $\ldots \ldots \ldots \ldots \ldots \ldots \ldots$

Japanese species only $\ldots \ldots \ldots \ldots \ldots \ldots \ldots \ldots \ldots \ldots \ldots$

Japanese and Australian species $\ldots \ldots \ldots \ldots \ldots \ldots \ldots$ 


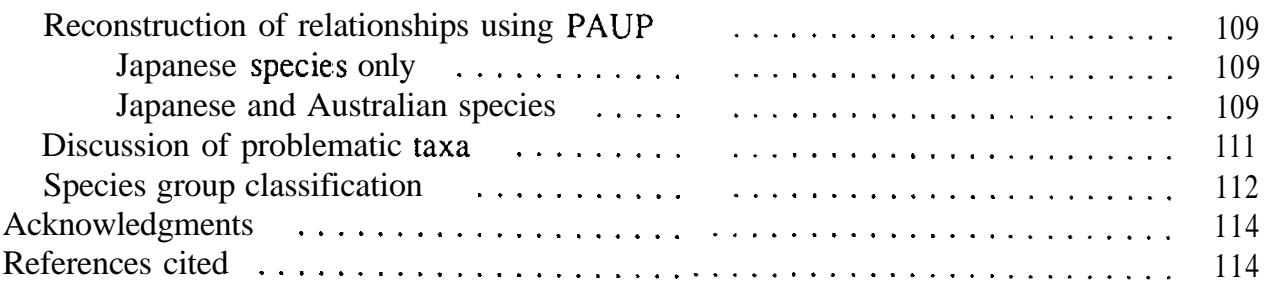

\section{INTRODUCTION}

The genus Bagous Germar is quite large, including well over 250 species. Treatment of Australian Bagous was the first phylogenetic study of Bagous weevils, and developed what we hoped would be a comprehensive basis for studying Bagous of other regions (O'Brien \& Askevold, 1992). Certain species of this fauna were known to be very closely related to species known from India (most of which are undescribed, based on an incomplete study of that fauna) and Southeast Asia. It was hoped that thorough phylogenetic treatment of the Australian species would provide a broad foundation for subsequent phylogenetic studies and classification of the Bagous of other regions. Inclusion of species from other regions would be a test of this reconstruction, as well as a test of the method of character analysis which we introduced there. We hypothesized that if our analysis of this fauna was a good approximation of relationships of its members, then species from other regions should fit well into this phylogenetic framework.

The purpose of the present publication is to analyze the relative relationship of members of Bagous known to occur in Japan, and is the second of several geographically focussed studies on this genus. The Japanese species are analyzed including the Australian species, to provide a more comprehensive phylogenetic "picture". This analysis is the basis for the classification and sequence of presentation of the Japanese species in the preceding taxonomic treatment that accompanies this study (O'Brien et al., 1994). Results presented here represent a small portion of a continuing, more geographically comprehensive study. It is not claimed here that all Japanese Bagous are as closely related to one another as depicted in figures of phylogenetic relationships. Rather, these illustrate relative phylogenetic positions of species known to occur in the Archipelago.

\section{MATERIALS}

This treatment is based on study of all described Japanese and Australian Bagous ( $c f$. O'Brien \& Askevold, 1992; O'Brien et al., 1994). Other Bagous of the world also formed a significant basis for character analysis (O'Brien \& Askevold, unpublished data).

Illustrations of genitalia of European Bagous (Caldara, unpublished data) provided information on many Palearctic taxa not yet studied by us and, for example, were the basis for discovering the close relationship of $B$. frir (Herbst) to the Japanese $B$. frirodes O'Brien \& Morimoto. Figure numbers greater than 10 cited in the text following refer to figures in the preceding taxonomic treatment of species of Japanese Bagous, unless another source is 
specifically cited.

PAUP Version 3.1.1 Update (Swofford, 1993) was run on a MacIntosh Quadra 700.

\section{METHODS OF PHYLOGENETIC ANALYSIS}

Below we present a number of aspects about systematics methods that we employ in studies of Bagous; one rarely finds such discussion in monographs such as this. It is typical, and generally acceptable for purposes of methodological validation, to state merely that the methods of Hennig $(1965,1966)$ are being used. The fundamentals of these methods are what systematists generally simply "do", but the methods are generally adjusted ad hoc to suit circumstance and need. This oft undefined approach lacks explicitness, but one is expected nonetheless to accept as valid the results of systematic work. Of necessity, it is the habit among many practitioners to be vague but this is undesireable because it contravenes the scientific method. Indeed, recent authors have decried this habit with respect to character analysis for phylogenetic reconstruction in particular, and have called for more fulsome discussion and rationale. It has been our habit to be explicit in phylogenetic reasoning (e.g. Askevold, 1988, 1990, 1991; O'Brien \& Askevold, 1992). A by-product of explicitness is that of being monitored and criticized, exemplified by Wharton $e t$ al. (1992), but the desired product of more closely approaching the truth is more likely to be realized. Research on systematics of weevils should be so closely examined.

Phylogenetic reconstruction.

Phylogenetic analysis was carried out according to the principles of phylogenetic systematics of Hennig (1966), discussed by Wiley et al. (1991) and modified specifically by Askevold (1991, pp 14, 88) and O'Brien and Askevold (1992, pp 406-408). O'Brien and Askevold (1992) introduced a method of character analysis (in transitumanalysis) which is modified in this analysis.

Polarity of character states was determined using in-group and out-group comparison criteria. In-group is defined as members of Bagous. In-group comparison consisted principally of comparison among other taxa within the genus, and of character correlation. Therefore, if the character in question was possessed by taxa that already possessed a suite of highly derived characters, then it was likely that this character, too, would be derived unless out-group comparison suggested otherwise. Conversely, if the character in question is possessed by taxa that are in general plesiomorphic, then it was probable that this character, too, would be plesiomorphic unless out-group comparison suggested otherwise. Out-group is defined as other weevils, with emphasis on Erirhininae sensu strictu, because the sister group of Bagous is not known.

Phylogenetic reconstruction was accomplished by two methods, manual reconstruction and computer-aided reconstruction. The latter method has the alleged advantage of objectivity in character assessment and calculation of tree length, with the added benefit of capacity to readily analyze large data sets. A hypothetical ancestor with all characters coded plesiomorphic, was used for PAUP analysis.

The former, manual method has the advantage of retaining the intuition and imagination of the systematist, whose accumulated knowledge is not necessarily explicitly brought to bear 
during the process of decision-making. This process is an interactive one, and was implied, but not at all discussed, by Hennig (1966), referring to the principle of "reciprocal illumination" or "reciprocal clarification". We ascribe to the viewpoint that both methods of reconstruction have validity and value, and. should be used as reciprocally illuminating tools, neither to the exclusion of the other. Thereby, we strive to retain the intangibles, but test and modify with the objectivity of parsimony introduced by computer analysis. To that end, we explicitly detail the method we have used; we do not consider it to be entirely novel because it was already alluded to by Hennig, but attempt to formalize, explain and validate it. In transitum analysis discriminates between characters of' unequal weight and nonhomology. Identification of nonhomology is fundamental to our method, and the recognition of nonhomology is accomplished during the overall process of analysis (hence, in transitum).

The objective of this method is to explain the data most reasonably and logically, and this may have little to do with strict application of parsimony. In manual reconstruction, this objective is accomplished by constructing the tree upward from the stem. A basal framework is established on the strength of highly "weighted" characters. Each major lineage is then resolved independently of others that branch off below; derived character states existing in multiple lineages must be homoplastic because more basal branches are defined by inviolable synapomorphies. Marshall (1987) and Anderson (1987) essentially used this method also.

In contrast, the ultimate objective of computer methods remains to generate a single most parsimonius tree, and this objective determines how the data are handled. Fan-is's (1969) method of "successive approximation" is analogous to ours in its methodologically reiterative approach. Successive approximation and other methods (e.g. Sharkey, 1989) use character weighting to reduce the number of possible trees generated and therefore have the same objective, but methods of weighting are different.

PAUP Version 3.1.1 Update (Swofford, 1993) was used as an analytical tool to examine character state distributions, to find alternative trees and to generate consensus trees for comparative purposes. Results presented were produced using the options MULPARS, ADDSEQUENCE=ASIS, DELTRAN optimization, and TBR branch-swapping. Other addsequence types and ACCTRAN optimization also were used for comparison of results. Heuristic, branch and bound, and exhaustive search algorithms were used as appropriate to size of the data set being analyzed: for Japanese species only, all functioned reasonably, but inclusion of Australian species became too large for the latter algorithms.

\section{In transitum character analysis.}

This method amounts to what is essentially character weighting with respect to result. However, we feel that neither the a priori nor a posteriori concepts of weighting apply to this method because "weighting" is done during overall iterative analysis. Analysis is a continuous process between the starting- and end-points, with consideration about phylogenetic value of characters being made during this process. Hence, we concluded previously, that recognition of a third conceptually different weighting method is appropriate, which more closely approximates and describes this process. This we named in transitum analysis, and identified the recognition of homology of apomorphic states as fundamental to this method. This recognition is accomplished iteratively during the entire study and therefore exactly fits no currently identified concept.

In transitum analysis equates well with the "principle of reciprocal illumination" or 
"reciprocal clarification", the meaning of which was implied but not discussed by Hennig (1966:148, 206, 222) (cf. also Wiley, 1981: 139) and which was not formally developed as a method of phylogenetic systematics. In general, workers often rely heavily on statistical methods that are available to influence tree length calculation (Farris, 1969; Sharkey, 1989) and to quantify accuracy, but there is no particular reason to presuppose that evolution in fact proceeds in this parsimony-based way. These methods compound one assumption over another iteratively because weighting is predicated upon previously weighted analysis, but do not establish explicit hypotheses of homology. In transitum analysis is also iterative and compounds deductions (assumptions), but differs in its explicitness.

It is contradictory to treat certain characters (homoplasies) conceptually as nonhomologous apomorphic occurrences, while retaining them as homologous single characters for analytical purposes. Character weighting by accepted methods attempts illogically what in transitum analysis accomplishes unequivocally, by explicitly discriminating nonhomologues and treating them as such. In transitum analysis reduces "the problem of homology", "the supposed incongruence between a theoretical definition and its practical application [which] has led many workers to abandon an evolutionary definition of homology" (Wiley, 1981:138).

Character states which appear to be modifications of the same structure but which are derived independently are homologous only in the sense that they apparently originate from a common structure. However, they are not homologous evolutionarily, having evolved asynchronously and among independent lineages, even should precisely the same genes be involved. Therefore, it is reasonable to consider these as independent characters because of independent evolutionary origin, and they should be treated methodologically as independent characters. Our method specifically seeks to cope with homoplastic characters by recognizing asynchronously evolved, apparently identical, apomorphic states. Such asynchronously evolved derived states must logically be treated as nonhomologues. Characters were assessed as nonhomologues in transitum, during a progressive, iterative sequence of analyses beginning with manual reconstruction, proceeding to analysis using PAUP.

Using previously hypothesized character polarity, and the taxonomic inclusiveness of a synapomorphy, the probable status of a homoplastic character state in a particular taxon (or group of taxa) could be judged. Homoplasy must be due either to 1) reversal or 2) convergence (=parallelism). 1) If the character state is the result of a reversal (secondary loss), then in fact that state is not a reversal to the true plesiomorphic state; rather, it is a modification to a more highly derived state that resembles the plesiomorphic state. Such characters could be treated essentially in a manner similar to that previously introduced as in transitum analysis. If it is concluded that possession of such a state must logically represent a reversal, then a derived character state was added to the data set, accordingly ( $c f$. char. 97, for example). 2) If the character state is the result of convergence, then the derived condition has been achieved independently, and (probably) also asynchronously (not at same time). Independent, asynchronous transitions cannot be homologous, and for this reason should be treated as nonhomologues.

We consider these treatments in transitum analysis because such changes are made during the series of manual and computer-aided analysis, not a priori. Characters treated in this way are identified explicitly in the character analysis. 


\section{Character weighting.}

For the most part it was not necessary to weight characters for PAUP analysis. However, the large number of homoplastic external characters (even though 70 of 127 characters are genital) did tend to skew analysis and force results suggesting unrealistic character transformations in certain genital characters (compare Figs. 7-10). This was especially true in analysis of Australian species. Therefore, characters were weighted equally, with the exception of characters 3 (basal spiculate sacule), 14 (dorsal process of median lobe), and 17 (denticles of dorsal process), which we consider to be fundamental. These were weighted heavily to force some basic topological constraints. Both weighted and unweighted analyses were performed.

Manual reconstruction required extensive character weighting, which is implicit in this method. Numerous character conflicts exist in the data. Our manual results reflect decisions made about probable homoplasy, as well as indecision for want of decisive data for some species (e.g. B. fractus O'Brien \& Morimoto).

\section{Use of autapomorphies.}

Autapomorphies are included for several reasons, although they obviously contribute nothing to resolution of relative relationships of the Japanese and/or Australian taxa. Many such characters are actually shared by taxa (which are known to us) occurring in other zoogeographic regions and therefore are only apparent autapomorphies. It is expected that additional species remain to be discovered, and presently striking autapomorphic characters may well be shared by some of these species. It is worth noting such characters in anticipation of discovery of additional taxa lest they be overlooked in future by other workers.

For practical reasons of computer analysis, characters that are derived for all taxa are also included. Although they contribute nothing to resolution of relationships, they represent hypothesized synapomorphies for the genus as presently defined. Their taxonomic inclusiveness remains open to reevaluation as taxa from other regions become added to the analysis. This analysis is ongoing as we strive to evaluate the higher classification among bagoines. Limits of the genus are not yet clearly defined and thorough consideration is important. A more extensive discussion about use of autapomorphies is provided by Yeates (1992).

\section{Treatment of taxa known only from one sex.}

We encountered analytical difficulties because of "missing" data for some species. In the course of studying genera such as Bagous, there remain species which, based on available material, are known from only one sex. This problem was also encountered in study of Australian Bagous (O'Brien \& Askevold, 1992). We have discovered that Marshall (1987) used the same logical approach to cope with taxa known from a single sex that we used previously (and herein). On the basis of genital and/or external morphology, we are confident that these species are distinct. On the basis of the principle of character correlation we could be confident about the relationship of at least some of these species to others which are known from both sexes. Such characters do not have to imply that the species which share these synapomorphies are sister taxa; taxa can be distantly related but within the same clade as evidenced by possession of synapomorphies. Therefore we believe that it is reasonable to assign these species assumed states for at least some genital characters. All such assumed characters are clearly indicated in boldface in the character analysis, below, and in the character matrix.

Six Japanese species are known from only one sex (B. occultus O'Brien \& Morimoto, B. 
rotundatus O'Brien \& Morimoto, males only; B. subcordatus O'Brien \& Morimoto, B. lewisi O'Brien \& Morimoto, B. tuberculosus O'Brien \& Morimoto, B. subvittatus O'Brien \& Morimoto, females only). Among the Japanese species, three species which are known only from female specimens could not be assigned to any species group (i.e., B. lewisi, B. tuberculosus, B. subvittatus), thus these were not included in the analysis. These species are assigned as species

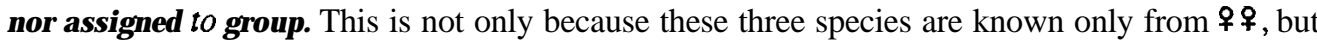
because they possess no apomorphies that unequivocally suggest a relationship. Other species, namely B. occultus, B. rotundatus and B. subcordatus possess characters, mostly genital, which indicate unequivocally by character correlation what certain character states must be. For example, B. subcordatus possesses two female genital characters that are possessed only by members of the B. bipunctatus group, thus a number of male character states can be assumed (for example, that the species does not possess a dorsal process of the median lobe).

All known species of the B. pygmaeus group have several character states of external structure (elytral scale arrangement, body size and shape, etc.) but mostly plesiomorphic characters of female genitalia. Thus a number of female genital character states were initially assumed for B. minor O'Brien \& Morimoto. During the writing of this paper, B. minor was known only from male specimens, and analysis was therefore carried out according to the above method. Assumed states were confirmed when females were subsequently found.

\section{Excluded taxa.}

Three taxa are excluded entirely from analysis: B. lewisi, B. subvittatus and B. tuberculosus, which are known only from female specimens. The most important characters, those of the median lobe, that are useful in unequivocally assigning these three species to a major lineage in the genus are therefore missing. Each of these species possesses one or more derived states of external characters that could be used to group each of these with one another, or with any of several other species that are unrelated to one another. Relationships are entirely equivocal and it would be neither informative nor profitable to include these species in analysis and to attempt to classify them to species group. For illustrative purposes, these species are placed in an intermediate position on interrupted, unconnected (unrooted) lineages (Fig. 1).

Rationale for geographically restricted study and analysis.

Many systematic revisions that include phylogenetic analysis undoubtedly do not include all described taxa, especially if groups are geographically widespread. This is so if only because it is quite possible that there have been extinctions within the group, and taxa are therefore missing (but this is not necessarily so and should not be assumed) (cf. Askevold, 1991:102). Secondly, in a group such as Bagous which are not especially commonly collected because considerable experience and specialization of technique are required to collect all but the most common of species, it is unlikely that all existing species will be available among museum holdings. In our study of Australian species of the genus, we noted that the preponderance of collection effort was concentrated in Queensland and the Northern Territory, and was concentrated upon habitats in which Hydrilla was found (cf. O'Brien \& Askevold, 1992:424). Thus, other regions, habitats and host plants have not been adequately sampled, probably on a world-wide basis. While we already recognize a number of species groups as distinct, we do not know the full geographic distribution of these groups because we have not studied all taxa in detail. Even if we did study all described taxa, this would give us a very incomplete picture; for 
example, 24 of 27 Australian and 15 of 17 Japanese species were described as new. Most species we know from the Indian Subcontinent are undescribed, and there are many others from other regions.

Thus, it can be argued that our sample of taxa is inadequate to accurately assess character polarities, and that the geographic scope is insufficient to encompass a broad enough phylogenetic spectrum of the genus. It can always be argued that one does not know enough to make meaningful phylogenetic statements, but it is more useful to draw conclusions about what one does know and to allow room for subsequent modification, than to conclude nothing for want of completeness. For practical reasons it is impossible at this time to analyze the entire genus Bagous comprehensively.

Our research is progressing on a geographic basis rather than a phylogenetic basis. That is, our research priority is predicated on geographic region of interest, and the taxonomic revisions of species of these areas need to be done first. In any case, it is not necessarily possible to extract single monophyletic groups arbitrarily within the genus, to carry out systematic revisions of them, and to analyze relationships within these monophyletic groups (e.g. species groups or subgenera). Besides, analysis of a geographic fauna selects a phylogenetic crosssection of the genus, especially if the fauna is of polyphyletic constitution. This equates with random sampling of a subset of a monophyletic group. Analysis of each geographic sample can be used as a test of the previous sample.

\section{Recognition of species groups.}

In discussion of characters below, reference is made to species groups. We recognize these groups despite lack of a reconstructed phylogeny of all Bagous because we have studied more than one-half of the described world species and are confident that these groups are phylogenetically well-founded. The groups are recognized a posteriori, according to groups discovered during and after analysis. We find naming these groups useful to communicate information, recognizing such groups on the basis of synapomorphies as detailed here.

No specific, uniformly applied criterion was used to name species groups. Instead, various criteria were applied. If a species had been described already then we believed the species would be more widely known to workers and it was selected. In the case of the $B$. pygmaeus group, the name of the nominal species is descriptive of the group, while the B. hydrillae group (Australian) is so named because B. hydrillae O'Brien is both economically important as well as representative of the majority of species of the group, and is most common in collections. In other cases, none of the included species have been described, thus the only described taxon must be nominal (e.g. the $B$. proprius group). In some cases only a single species is known (e.g., $B$. rotundatus), in which case this becomes the nominal taxon for the monobasic group.

Not all species groups with which we are familiar bear on the present analysis. Some species groups are not represented in the Japanese fauna, nor in the Australian fauna. However, some taxa do bear on character polarity decisions, thus their consideration is important. This is particularly so for the B. crispus group. Insofar as discussion and character analysis pertain here, we recognize at least 14 species groups:

1) B. crispus group, based on B. crispus Faust (African), including B. brevipennis Kirsch (Caucasus), B. luteitarsis Hustache and B. ovoideus Hustache (India) and several other African species; none occur in Japan;

2) B. pygmaeus group, based on B. pygmaeus Voss (Sumatra), including B. clarenciensis 
Blackburn (Australia), B. nodieri Hustache (Viet Nam), B. minor and B. pygmaeodes O'Brien \& Morimoto (Japan), 3-4 undescribed Indian species and probably others;

3) B. hydrillae group, based on B. hydrillae including 19 Australian species;

4) B. bipuncratus group, including B. kagiashi Chûjô and Morimoto, B. bipuncratus (Kôno) and four other Japanese species, but there appear to be numerous species in other regions that belong to this complex;

5) B. humeridens group, based on B. humeridens Hustache (India), including B. utriculariae O'Brien (Australian);

6) B. apicalis group, based on B. apicalis O'Brien (Australia), including an undescribed Indian species;

7) B. proprius group, based on B. proprius O'Brien \& Morimoto (Japan), including at least one undescribed species from India and Viet Nam;

8) B. buckinghami group, based on B. buckinghami O'Brien \& Morimoto (monobasic, Japan), but probably contains species from other regions;

9) B. fractus group, based on B. fractus (monobasic, Japan), but probably contains species from other regions;

10) B. rotundatus group, based on B. rotundatus (monobasic, Japan), but probably contains species from other regions;

11) B. transversus group, based on the Nearctic species, B. transversus (LeConte), including B. youngi O'Brien \& Morimoto (Japan) and at least one undescribed Indian species;

12) B. frit group, based on B. frit Herbst (Europe), including B. fritodes (Japan);

13) B. addai dae group, based on $B$. addaidae Blackburn, including two other Australian species;

14) B. trapae group, based on B. trapae Parshad (India), including B. natator O'Brien \& Morimoto (Australia) and several Southeast Asian and African species, but none are known to occur in Japan.

The ground plan is derived for each species group by assigning states that are plesiomorphic andlor synapomorphic for the group.' Thus, though some, if not even most included taxa possess more highly derived states (often homoplastic within and without the group), the group is assigned states that the stem of the group as a whole possesses. This ground plan represents the diagnosis that is used to define the species group in the taxonomic treatment.

\section{CHARACTERS USED IN PHYLOGENETIC RECONSTRUCTION.}

Characters used for phylogenetic analysis are listed below, beginning with male and female genital characters, followed by external characters. In keeping with recent recommendations in systematics we are thorough (if not verbose) in our character analysis, for there is no other means to adequately convey the reasoning for character polarity, etc. The structure is defined, followed by its hypothesized plesiomorphic state and derived state(s), basis for polarity, then a brief discussion and statement of phylogenetic inclusiveness and hypothesized homoplasy. The character set used here is part of a larger growing set being developed during study of world Bagous, but only those characters which affect determination of relationships among Japanese 
and Australian Bagous are used here, numbered sequentially.

The character set excludes characters that do not apply to taxa newly included in the present analysis. Such characters are synapomorphies for other extralimital species groups, or they have been discussed previously (O'Brien \& Askevold, 1992). Thus there are gaps in the character sequence (e.g. \#5-7, 10-11), and it should be understood that these gaps are purposeful.

Changes in interpretation of character states for Australian species are indicated in discussion below; there are few such changes, but some are significant. Figure numbers other than those referring to the cladograms refer to the preceding taxonomic treatment of the species (O’Brien et al., 1994, i.e., Figs. 35 and higher).

The character set we used for Australian species consisted of 54 characters (O'Brien \& Askevold, 1992). With inclusion of the Japanese fauna in phylogenetic analysis, the character set has greatly expanded. To ensure accurate tracing of use of these characters, we indicate for each character, what the character number was in this monograph. We used DELTA (Dallwitz \& Paine, 1986; Partridge $e t$ al., 1988) to "manage" the data set as it expanded (Askevold and O'Brien, 1994). Thus, for each of these characters we state what the character number in that study was because this number may not be the same now (because we used only 54 characters in that study, but now have 127). As the scope of analysis changed, so did some conclusions we came to before, or the reasoning we used changed.

Characters are presented in numerical order, beginning with male genitalia, then female genitalia, and finally external characters. The list represents the characters we are presently considering for phylogenetic purposes; characters that are not applicable to species under consideration in this paper are omitted here. Thus, characters are not included in the data set. This is done to minimize frequency of modification of character sequence as the number of characters increases, and the logical sequence changes.

\section{MALE GENITAL CHARACTERS.}

1. Sub-orificial sclerites (Character 1 in O'Brien \& Askevold, 1992).

0 . Internal sac without complex sclexites behind orifice.

1. Internal sac immediately behind orifice with U-shaped, hooked process.

Two species (B. humeridens and B. utriculariae) possess a curious, hook-shaped process near the orifice. This structure is unusual in Bagous and other weevils in general. We therefore consider this structure synapomorphic for the $B$. humeridens group. Basis for polarity: in-group and out-group comparison.

2. Subbasal spicules of internal sac (Character 2 in O'Brien \& Askevold, 1992).

0 . Internal sac without subbasal pair of concentrations of spicules.

1. Internal sac with subbasal pair of dense concentrations of elongate spicules.

A group of Australian species possess a subbasal pair of concentrations of elongate, curved spicules which appear under low magnification like sclerites. Their appearance can be altered by basal deformation of the sac basally. This structure is unusual in Bagous and other weevils in general. Presence of these spicules is considered synapomorphic for 18 Australian species of the B. hydrillae group, excluding B. pauxillulus O'Brien. Basis for polarity: in-group comparison. 
3. Basal, spiculate sacule (Character 3 in O'Brien \& Askevold, 1992).

0 . Base of internal sac without sacule containing spicules.

1. Base of internal sac with sacule containing elongate, curved spicules forming dark, somewhat paired mass.

A group of Australian species possess a basal sacule containing elongate, curved spicules, which may not be visible under low magnification. Their appearance can be altered by basal deformation of the sac, or the sac may be detached during dissection. This structure is unusual in Bagous and other weevils in general. Presence of this spiculate sacule is considered synapomorphic for 19 Australian species comprising the B. hydrillae group. Basis for polarity: in-group comparison.

8. Shape of apical sclerites (Character 5 in O'Brien \& Askevold, 1992).

0 . Orificial sclerites, if evident, flat, with base and apex in more or less same plane.

1. Orificial sclerites basally recurved upwards and markedly sclerotized.

In a small group of species the base of the orificial sclerites is markedly sclerotized, upturned, and therefore prominent. This structure is unusual in Bagous and other weevils in general. This state is considered synapomorphic for the group of species including B. natator (Australia) and other species occurring in India, a subset of the B.trapae group. Basis for polarity: in-group comparison.

9. Orificial spicules (Character 6 in O'Brien \& Askevold, 1992).

0 . Spicules around orifice small or absent.

1. Spicules around orifice enlarged, arcuate and serially arranged.

Presence of enlarged curved spicules is unusual in the genus Bagous, known only in $B$. apicalis; an undescribed species from India is very closely related to B apicalis as evidenced by other characters but does not possess these spicules. This structure is unusual in Bagous and other weevils in general. Other, unknown Australian species may be more closely related, and may possess these spicules also. Basis for polarity: in-group comparison.

12. Internal sac armature (Figures $41-45$, sf).

0 . Internal sac simple, spicules and denticles distributed more or less uniformly, not forming large, concentrated areas.

1. Internal sac with pair of lateral elongate-oval concentrations of numerous fine to coarse, mostly acute denticles.

2. Internal sac with pair of lateral concentrations of relatively few, very large, acute denticles.

Among Bagous known to us, presence of distinct concentrations of denticles on the internal sac is unusual. The internal sac typically has denticles that can be seen at high magnification, but the distribution is generally uniform. This particular arrangement is unusual in Bagous and other weevils in general. Thus, we consider the presence of such denticle concentrations apomorphic. Basis for polarity: in-group and out-group comparison.

A number of Japanese species possess such denticle concentrations and we consider this character synapomorphic for these species (12'). Species such as B. vicinus Hustache (India) and B. occultus, on the basis of character correlation, appear to belong to the group of species possessing $12^{1}$, but the internal sac possesses a field of very large teeth in the location of the 
denticle concentrations found in other species. Therefore, we conclude secondarily that this state is a further modification of this character and assign them $12^{2}$. We therefore consider 12' synapomorphic for the B. bipunctatus group, with $12^{2}$ possessed by B. occultus; B. vicinus also probably belongs to this group.

13. Dorsal plate of orifice (Character 7 in O'Brien \& Askevold, 1992).

0 . Median lobe: without dorsal plate over orifice.

1. Median lobe: with more or less horizontal, broad, single plate over orifice.

Two species (B. apicalis group) possess a plate that fits in the orifice. This structure is unusual in Bagous and other weevils in general. Therefore we consider this structure synapomorphic for this group. Basis for polarity: in-group and out-group comparison.

These species seem to belong to a large, almost world-wide group of species possessing a dorsal process. Species hitherto placed in B. (Ephirneropus) Hochhut (as evidenced by an undescribed Indian species) possess a similar but moveable vertical process as well as a median setal brush. We speculate that this orificial plate may be a precursor to the dorsal process, with the state possessed by this and possibly other species as intermediate. Therefore, it is possible that the sclerite here described is basal in a longer transition series.

14. Dorsal process of median lobe (Character 8 in O'Brien \& Askevold, 1992) (Figures 46-50, $55, \mathrm{dp})$.

0. Median lobe without dorsal process.

1. Median lobe with post-orificial dorsal process, directed more or less vertically.

2. Median lobe with dorsal process almost horizontal, directed distally.

A large group of species possess a process (typically immoveable) which arises from and is distinctly attached to each posterolateral angle of the orifice. No similar process is known to us among other weevils. Basis for polarity: in-group and out-group comparison.

Typically the process is directed vertically or slightly in either a distal or proximal direction (14') but in a few species it is directed distally, almost horizontally, and extends well over the orifice $\left(14^{2}\right)$. Presence of a dorsal process is considered synapomorphic for a large, monophyletic and widely distributed group of taxa. State $14^{2}$ is synapomorphic for the B. trapae group; members of the B. proprius group have what could be considered a similar arrangement, but for the present we consider these to be 14 '.

15. Dorsal surface of median lobe, behind dorsal process (Character 9 in O'Brien \& Askevold, 1992) (Figures 46-50, 55, dn).

0 . Median lobe dorsally convex behind dorsal process.

1. Median lobe with broad depression behind dorsal process.

Species possessing a dorsal process generally also have a shallow to marked depression behind this dorsal process; this depressed area may be largely membranous or fully sclerotized. It is highly modified in an Indian species, forming a uniformly deep and broad sulcus to the posterior margin. The depression is considered synapomorphic for species also possessing a dorsal process. Basis for polarity: in-group and out-group comparison. 
16. Median setal brush of dorsal process (Character 10 in O'Brien \& Askevold, 1992) (Figures 47-50, 55, msb).

0 . Dorsal process without median setal brush.

1. Dorsal process with median setal brush situated on anterior surface of process.

2. Dorsal process with median setal brush situated on ventral surface.

3. Dorsal process with setal brush situated along ventrolateral margin.

Species possessing a dorsal process also have a brush of dense, long setae on this process. Typically these setae form a dense median brush on the anterior surface of the dorsal process, projecting distally (16'). This is also true of B.(Ephimeropus), though the "process" is not formed the same way (see character 13). Some species have this brush situated on the ventral, median surface $\left(16^{2}\right)\left(B\right.$.trapae), or on the ventrolateral surface $\left(16^{3}\right)$ (B. natutor). Possession of the setal brush is considered synapomorphic for species also possessing a dorsal process, excluding only the $B$. proprius group which lacks the brush. Basis for polarity: in-group and out-group comparison.

17. Inner surface of dorsal process (Figures 47, 49, 50, d).

0 . Inner surface of dorsal process lacking denticles.

1. Inner surface of dorsal process covered with dense area of denticles.

The dorsal process generally has a smooth inner surface. Some species, however, appear to have the dorsal process open above, and the inner surface denticulate. Such denticles are visible only at high magnification. Because such denticles are unusual among Bagous, we consider this state synapomorphic for a number of species occurring in geographically disjunct regions, including B. rotundutus, B. young $i$ and B. fritodes in Japan and B. trunsversus in North America, and at least one undescribed Indian species. Basis for polarity: in-group comparison.

The species possessing this character differ greatly in body form or other genital characters (contrast B. fritodes and B. rotundutus, for example), and therefore we assign them to distinct species groups. The median lobe of B . fritodes is similar to B. frit, among Palearctic species; that of B. young $i$ is most similar to the Nearctic species, $B$. trunsversus and an Indian species, while $B$. rotundutus has no closely related species with which we are familiar.

\section{Margin of median lobe at base of dorsal process (Figure 49, li).}

0 . Lateral margin of median lobe simple.

1. Lateral margin of median lobe with subapical lateral incision.

Among species of Bugous possessing a dorsal process, possession of a deep incision at the base of the dorsal process is unusual. It is also not found among weevils in general. We therefore consider this state synapomorphic for the species possessing it, comprising the $B$ trunsversus group. Basis for polarity: in-group comparison.

\section{Sublateral margin of median lobe, behind dorsal process (Character 11 in O'Brien \&} Askevold, 1992) (Figure 50).

0 . Median lobe dorsally uniformly rounded behind dorsal process.

1. Median lobe with dorsal, sublateral, carinate, denticulate ridge bordering median depression behind dorsal process.

In several Australian species, the depression behind the dorsal process is laterally bordered by a well-defined, carinate, denticulate ridge. This structure is unique among Bagous and weevils 
in general. We therefore consider it synapomorphic for a group of three Australian species, forming the B. adelaidae group (O’Brien \& Askevold, 1992). Species of the B. frit group also have a similar structure, but the ridges are $\mathrm{V}$-shaped and probably independently developed. Basis for polarity: in-group and out-group comparison.

22. Posterolateral dorsal angulation of median lobe (Figure 45, sam).

0 . Median lobe dorsolaterally uniformly convex in posterior half.

1. Median lobe with posterolateral, dorsal, angulate ridge from orifice to posterior margin.

The median lobe of Bagous and other weevils is normally rather uniformly convex behind the orificial area, among species lacking a dorsal process. A single species, B. bipunctatus, possesses a rather distinct subcostate sublateral angulation, extending from the orificial area to the posterior margin, which is clearly apomorphic. Basis for polarity: in-group and out-group comparison.

This character is known only in the single Japanese species. However, B. subcordatus, known only from female specimens, appears to be most closely related to $B$. bipunctatus on the basis of character correlation. We therefore expect to find that $B$. subcordarus will also possess this character, if males are discovered subsequently.

24. Sclerotization of dorsal surface of median lobe (Character 12 in O'Brien \& Askevold, 1992).

0. Dorsal surface with sclerotization not evident.

1. Dorsal surface fully sclerotized at least basally.

Among the majority of Bagous, the dorsal surface, excluding the subapical orifice, of the median lobe is fully sclerotized. This is typical primarily of advanced weevils (e.g. many Cryptorhynchinae, most Cossoninae, etc.). We consider full sclerotization of the dorsal surface (exclusive of the orifice) synapomorphic for the genus Bagous. Among at least two, unrelated groups of species, the apparent orificial area is greatly enlarged and gives the appearance of a large orifice, or even that the dorsal surface is not sclerotized, but generally there is at least a narrow area of sclerotization basally (e.g. B. affinis Hustache, B. josephi O'Brien, B.hydrillae, B. laevigatus O'Brien \& Pajni). Basis for polarity: out-group comparison.

25. Sclerotization of ventral surface of median lobe (Character 13 in O'Brien \& Askevold, 1992) (Figure 41).

0 . Ventral surface fully sclerotized.

1. Ventral surface broadly membranous, from base to near apex.

Among the majority of Bagous and other advanced weevils, the ventral surface of the median lobe is fully sclerotized. We therefore consider a membranous ventral surface derived. Basis for polarity: in-group and out-group comparison.

Among Australian Bagous, B. blyxae O'Brien and B. marrhewsi O'Brien share a membranous venter, and therefore we consider this state synapomorphic for this group of species, also presumably including B. blyxodes O'Brien. This apomorphic state is assumed in $B$. blyxodes, which is most similar to B. blyxae in external characters. Other taxa with this character are B. josephi (Australia) and B. kagiashi (Japan). 
26. Shape of venter of median lobe (Character 14 in O'Brien \& Askevold, 1992).

0 . Ventrolaterally median lobe uniformly rounded.

1. Ventrolaterally median lobe triangular in cross-section, in about middle region.

This median lobe shape is unusual in Bagous and other weevils in general. Two known species (B.apicalis group) possess a median lobe which is markedly triangular in cross section below the orificial area. We therefore consider this shape synapomorphic for this pair of species. Basis for polarity: in-group and out-group comparison.

27. Dorsal, basal margin of median lobe (Character 15 in O'Brien \& Askevold, 1992) (Figures e.g. 42, 44-48, 50, 55).

0 . Basal margin dorsally truncate.

1. Basal margin dorsally deeply emarginate.

The basal margin of the median lobe of Bagous and weevils in general is typically truncate, to slightly emarginate. A markedly emarginate basal margin occurs among several independent lineages, and we consider this state synapomorphic separately for several groups of species: the group comprising the B. humeridens group + B. apicalis group + groups of species possessing a dorsal process. The derived state also occurs in several species of the $\mathbf{B}$. hydrillae group and other, unrelated groups of species occurring in other zoogeographic regions but nevertheless supports the first groupings discussed here. A reversal in the B. proprius group is required to explain the data. Basis for polarity: in-group comparison.

28. Ventral, basal margin of median lobe (Character 16 in O'Brien \& Askevold, 1992) (Figures 46-50, 55).

0 . Basal margin ventrally truncate.

1. Basal margin ventrally deeply emarginate.

The ventral basal margin of the median lobe of Bagous and weevils in general is typically truncate, though not necessarily distinctly sclerotized. Some species possess a distinctly emarginate ventral basal margin. Previously, we considered the derived state synapomorphic for the B. apicalis group and the large group of species with a dorsal process; we consider this state synapomorphic for this group of species. Independent occurrences of this state are found in unrelated taxa. In this analysis, we conclude that the state is independently derived in and synapomorphic for the B.apicalis group, and that it is collectively synapomorphic for the groups of species that possess a dorsal process. Basis for polarity: in-group comparison.

\section{Ventrobasal margin (Figures $42,44-45$, bp).}

0 . Median lobe with basal margin not extending posteriorly.

1. Median lobe with short, basal plate extending between apodemes, therefore visible from above.

2. Median lobe with short, basal plate extending between apodemes forming acute median point, visible from above.

Among Bagous, many species possess a rather distinct, ventral plate that extends the proximal ventral margin between the apodemes. Often, the dorsal, basal margin is emarginate or recessed, distinctly exposing the ventral margin. Here, however, the ventral margin is further extended between the apodemes, beyond the point of attachment of the apodemes ( $c f$. O'Brien er al. 1993, Fig. 41, for definition). This character is not known outside the genus, and we 
therefore consider the basal plate apomorphic. Basis for polarity: in-group and out-group comparison.

At this time we are not able to make decisions about grouping of taxa' on the basis of this character. There are species in all geographic regions except Australia that possess such a plate, but the scope of our analysis is insufficient to decide confidently on groupings. At least among Japanese species, four species can be grouped in the same lineage on the basis of this character.

A more derived state $\left(29^{2}\right)$ is possessed by some undescribed species from India. They possess the basal plate, but the plate is additionally medially pointed. This character state groups these species, but it may be independently derived.

30. Shape of ventral surface of median lobe, basally (Character 17 in O'Brien \& Askevold, 1992).

0 . Venter of median lobe uniformly rounded.

1. Basoventral area of median lobe medially depressed, ventrolaterally slightly costate at base.

2. Basoventral area of median lobe medially depressed and indistinctly sclerotized, ventrolaterally distinctly bicarinate from apodeme to about one-third length of median lobe.

The median lobe is typically convex or flat ventrobasally in Bagous and other weevils in general. Modification of the ventral surface is therefore derived. Basis for polarity: in-group and out-group comparison.

In species of the B. apicalis group, and many of the species possessing a dorsal process, the median lobe is basally depressed, and therefore somewhat costate laterally (30'). We consider this state independently synapomorphic for the B. apicalis group and for species with a dorsal process. Among species that possess a dorsal process, this depression can be much more marked, forming a more distinct sublateral costa or carina from the apodeme to about midlength or even below the orifice (3d) (Fig. 48, vc). Previously, we considered this state synapomorphic for the group of species possessing a dorsal process. With inclusion of additional taxa, it is more reasonable to consider that $30^{2}$ is derived in more than one lineage: in the B.apicalis group, and in the lineage of species with a dorsal process exclusive of the B.proprius group. A reversal must be invoked in $\mathbf{B}$. rotundatus.

31. Shape of venter of median lobe (Character 18 in O'Brien \& Askevold, 1992).

0 . Ventrolaterally median lobe uniformly rounded, without oval lobe.

1. Ventrolaterally median lobe with oval lobe in apical third.

This structure is unusual in Bagous and other weevils in general, and is therefore derived. Basis for polarity: in-group and out-group comparison.

Two known species possess a singular shape of the median lobe, forming an oval, ventrolateral lobe that is visible from above. The B. humeridens group is defined by this synapomorphy, supported by a number of concordant characters.

32. Shape of apex of median lobe (Character 19 in O'Brien \& Askevold, 1992) (Figure 50).

0 . Apex of median lobe uniformly rounded or tapering.

1. Apex of median lobe tapering, with extreme apex explanate (subapically constricted). This shape of the apex of the median lobe is unusual in Bagous and other weevils in 
general. Therefore it is derived. Basis for polarity: in-group and out-group comparison.

A number of unrelated species of Bagous possess a tapering median lobe, with the extreme apex explanate. Among Australian taxa, B. apicalis and B. simulans O'Brien possess this state, independently derived in each. Among Japanese species it is found in B. fritodes, which is unrelated to these species. Therefore this character does not contribute to resolution of relationships. However, it is possessed by both species of the B. apicalis group and of the B. frit group, and we consider it synapomorphic for each group.

33. Shape of apex of median lobe (Character 20 in O'Brien \& Askevold, 1992) (Figure 42).

0 . Apex of median lobe uniformly rounded or tapering.

1. Apex relatively acute.

This shape of the median lobe is unusual in Bagous and other weevils in general. Basis for polarity: in-group and out-group comparison.

A markedly acute apex of the median lobe (dorsal aspect) occurs in the Australian species $B$. josephi, which is also unusual in several other characters. While inclusion of this character contributes nothing to resolving relationships, we expect other species may be found in Australia that will share it and which will be closely related. In Japan, only B.occultus has a quite acute median lobe, but its apparent relatives do not.

34. Lateral margin distad of orifice (Figure 49, 50, d).

0 . Lateral margin laterad and distad of orifice smooth.

1. Lateral margin laterad and distad of orifice denticulate.

In Bagous and generally among weevils, the surface of the median lobe is smooth. Among some Bagous it is strigate, but presence of denticles is unusual and we therefore consider this character apomorphic. Basis for polarity: in-group and out-group comparison.

Among several Bagous occurring in Japan, India, Europe and North America, the median lobe is minutely denticulate laterad and distad of the orifice (visible only at high magnification). We consider this character synapomorphic for the B. transversus group + B. frit group.

36. Apex of median lobe (Character 22 in O'Brien \& Askevold, 1992) (Figure 50).

0 . Median lobe with apex symmetrical.

1. Median lobe with apex asymmetrically deflected to left.

This shape of the apex of the median lobe is unusual in Bagous and other weevils in general, and is therefore apomorphic. Basis for polarity: in-group and out-group comparison.

A tapering median lobe deflected slightly to markedly asymmetrically to the left occurs among a number of unrelated taxa or groups of taxa. Species of the B. apicalis group share this state. Otherwise, the asymmetrical apex occurs among unrelated taxa and is homoplastic (e.g., B. simulans, Australia, and B. fritodes, Japan). Species of the B. transversus group are very slightly asymmetrical, but we do not include these taxa in this state.

37. Length of pseudo-orifice (Character 23 in O’Brien \& Askevold, 1992) (Figures 39-41, 4445, pso).

0. Median lobe without pseudo-orifice, apparent orifice less than one-third length of median lobe.

1. Median lobe with pseudo-orifice short, apparent orifice very slightly extended 
proximally.

2. Median lobe with pseudo-orifice of moderate length, apparent orifice moderately extended proximally.

3. Median lobe with pseudo-orifice large to very large, apparent orifice markedly extended proximally.

Among Bagous, the proximal (anatomically anterior) orificial margin is defined by the point of inversion of the membrane of the internal sac (Fig. 43, porn). Typically this margin is defined also by a distinct margin of sclerotization. In a group of Australian species, a pseudo-orifice extends toward the basal margin of the median lobe to varying extents. We consider 37' synapomorphic for the B. hydrillae group and for a subset of species in each of the B. pygmaeus and B. bipunctatus groups. States $37^{2}$ and $37^{3}$ somewhat serve to group taxa within this otherwise largely unresolved group. A similar pseudo-orifice is found in B. josephi and B. pauxillulus, assigned $37^{3}$, but it is formed quite differently and these occurrences are judged homoplastic. This state is markedly formed in B. josephi and should be expected to occur in other species closely related to it (though there are none presently known). In the B. bipuncratus group $37^{1}$ groups a subset of taxa, but a reversal is invoked in B.occultus to explain the data. Basis for polarity: in-group comparison.

38. Form of apodemes (Character 24 in O'Brien \& Askevold, 1992) (Figures 46-50, 55).

0 . Median lobe with apodemes long, slender, usually at least one-half as long as median lobe.

1. Median lobe with apodemes short, markedly curved and apically inflexed.

2. Median lobe with apodemes short, with extreme apex sinuate.

3. Median lobe with apodemes extremely short, almost obliterated.

Typically, apodemes of male Bagous and other weevils are long, relatively straight (excepting the usual sinuation, e.g. Fig. 43) and slender, though there is considerable variation in length (Fig. 39 vs Fig. 40). Therefore we consider this form plesiomorphic. Basis for polarity: in-group and out-group comparison.

In Bagous, there is a tendency to shorten and to develop a marked convergence of the apodemes (Figs. 47-49, 55). This form occurs in three groups of taxa, the B. humeridens and $\mathbf{B}$. apicalis groups, plus all species with a dorsal process of the median lobe. We consider the shortened, markedly incurved and apically inflexed apodemes (38') synapomorphic for these groups together. Some taxa possessing a dorsal process have the extreme apex of the apodemes sinuate $\left(38^{2}\right)$, considered synapomorphic for species of the B. trapae group. Possession of this state by B. simulans and B. rotundatus is clearly homoplastic, because they are not closely related to the B. trapae group.

42. Dorsal longitudinal furrows of median lobe (Character 25 in O'Brien \& Askevold, 1992) (Figure 46).

0 . Median lobe without dorsolateral, longitudinal furrow extending from post-oriticial area to base.

1. Median lobe with dorsolateral furrow, extending from depression behind dorsal process to basal margin or nearly so.

2. Median lobe with dorsal furrows confluent and deep, extending from dorsal process to basal margin, forming a single broad sulcus. 
Among species possessing a dorsal process of the median lobe, the depression behind the process can be extended proximally as a pair of sulci between which the surface is markedly convex. Among Australian species, only B. natator and B. dostinei have these sulci. Among Japanese species, the state occurs in B. proprius. None of these are closely related species. Basis for polarity: in-group and out-group comparison.

44. Shape of median lobe immediately proximad of dorsal process (Figure 47).

0 . Median lobe more or less parallel-sided.

1. Median lobe broadened immediately proximad of dorsal process.

Among Bagous which possess a dorsal process, the median lobe becomes constricted somewhat proximad of the process; in some species it tapers, in others it is abruptly constricted. Therefore we consider a broadened median lobe apomorphic. This condition only occurs in the single Japanese species, B. rotundatus. Many species of Japan have relatives in other geographic areas, and we expect that relatives of this species will be found outside Japan that share this character. Basis for polarity: in-group comparison.

\section{Shape of median lobe immediately proximad of dorsal process (Figure 49).}

0 . Median lobe more or less parallel-sided at midlength.

1. Median lobe markedly constricted immediately proximad of dorsal process.

Among Bagous which possess a dorsal process, the median lobe becomes somewhat, generally gradually, constricted proximad of the process. In several species it is abruptly constricted, and we consider this condition apomorphic. This character is synapomorphic for members of the B.transversus group. Basis for polarity: in-group comparison.

\section{Thickness of median lobe (Figures 40, 42).}

0 . Median lobe more or less cylindrical, though oval in cross-section.

1. Median lobe compressed, dorsoventrally flattened.

Among Bagous and weevils in general, the median lobe is rather cylindrical. A markedly compressed median lobe is therefore apomorphic. Among Japanese Bagous this character occurs in two very unrelated species, B. pygmaeodes and B. occultus. Basis for polarity: in-group and out-group comparison.

48. Shape of median lobe, basally (Character 27 in O'Brien \& Askevold, 1992) (Figures 41, 43-44).

0. Median lobe basally about as broad as apically in area of orifice, more or less parallelsided.

1. Median lobe basally markedly widest, tapering toward apex, becoming parallel-sided in area of orifice.

Among most Bagous, excepting species possessing a dorsal process, the median lobe is rather parallel-sided basally. In a group of three Australian species (B. fornoae, B. meridionalis and B. rieki), and several Japanese species, the median lobe is markedly widest basally, the margins tapering toward a parallel-sided apical portion. We consider this shape synapomorphic for each of these group of species. A reversal is needed within the B. bipunctatus group to explain the data. Basis for polarity: in-group comparison. 
50. Shape of venter of apex of median lobe (Figure 42).

0 . Venter of apex of median lobe flat to convex, at most slightly depressed.

1. Venter of apex of median lobe with prominent tubercle, accentuated proximally by marked depression.

Among Bagous and weevils in general the apex of the median lobe tapers and is smooth. Therefore this condition is considered plesiomorphic. Basis for polarity: in-group and out-group comparison.

Some species possess a distinct ventroapical tubercle, which is accentuated proximally by a depression. We consider this condition apomorphic. Among Japanese Bagous this is possessed only by B. occultus, but this character also occurs in several North American species; probably it will be found also in Palearctic species. Presently, relationships are not resolved on the basis of this character.

51. Orifice of median lobe (Figures $42-43,45$, porn).

0 . Proximal margin of orifice simple, indistinct.

1. Proximal margin of orifice more or less straight, distinctly sclerotized.

Among Bagous and weevils generally the proximal orificial margin is usually membranous; therefore it is indistinct and is visible only at high magnification (see also char. 37). In some species this margin is distinctly sclerotized and therefore clearly visible. This we consider apomorphic. Basis for polarity: in-group and out-group comparison.

Probably this is indicative of a well-developed dorsal sclerite of the internal sac, located at the base of the sac at the point at which it invaginates. We consider this character apomorphic, and several Japanese and North American species possess it. Among Japanese species there are conflicting characters, and it appears that this may have arisen independently in two lineages within the B. bipunctatus group; we assume for the present that this is the case.

\section{Median lobe shape (Figure 50).}

0 . Median lobe cylindrical to subcylindrical in cross-section.

1. Median lobe T-shaped in cross-section, the sides deeply compressed behind dorsal process and almost meeting at midline.

Among Bagous and weevils in general the median lobe is generally cylindrical. However, in two species (that we know of), it is markedly laterally compressed in a very unusual way, producing a T-shaped cross-section; compression is so extreme that the sides almost meet, internally. We consider this character synapomorphic for the B. frit group. Basis for polarity: in-group and out-group comparison.

\section{Proximal margin of pseudo-orifice (Figure 45).}

0. Proximal margin of pseudo-orifice arcuate and concave, or more or less straight, if at all evident.

1. Proximal margin of pseudo-orifice arcuate, strongly convex.

Among species which have a pseudo-orifice (see char. 37), the proximal margin is generally concave or somewhat straight. In some species, this margin is distinctly convex. We consider this state apomorphic. Among Japanese Bagous, this is found only in B. bipunctatus; it occurs in some North American species, but these may not be closely related. Basis for polarity: ingroup comparison. 


\section{FEMALE GENITAL CHARACTERS.}

58. Form of arms of sternum VIII (Character 28 in O'Brien \& Askevold, 1992) (Figures 53, $57, \mathrm{fn})$.

0. Arms broad, and divergent or subparallel to apex.

1. Arms apically and broadly fused, but with small to large membranous fenestra.

2. Arms fully and broadly fused along entire length, fenestra closed.

Typically among species of Bagous and weevils in general, the arms are broad, with inner margins divergent or subparallel and not enclosing a fenestral area that appears like a hole at low magnification (Figs. 53, 57). We therefore consider fusion of arms apomorphic. Basis for polarity: in-group and out-group comparison.

In certain species, the arms are apically fused, leaving a membranous fenestra. This state is considered synapomorphic for a group of species that includes B.natator and at least two other undescribed species known from India. In one of these, the fenestra is completely closed, forming a broad solid spatulate sternum $\left(58^{2}\right)$. Two unrelated Japanese species possess $58^{1}, B$.proprius and B. fractus. The other known, but undescribed, species of the B. proprius group has normal unfused arms.

61. Form of arms of sternum VIII (Character 29 in O'Brien \& Askevold, 1992).

0 . Arms with inner margins divergent or subparallel to apex.

1. Arms strongly convergent, meeting at ca. midlength, with sclerotized area broad.

2. Arms strongly convergent, meeting at ca. midlength, with sclerotized area narrow.

Typically among species of Bagous and weevils in general, the arms are broad, with inner margins divergent or subparallel. In one small group of two known species (B. humeridens group), the arms are strongly convergent basally, meeting about midlength and enclosing a diamond-shaped fenestral area. In B. humeridens (India), the distal area of the arms remains broadly sclerotized (61'). In the Australian species, B. utriculariae, the sclerotized area is greatly narrowed $\left(61^{2}\right)$. Basis for polarity: in-group and out-group comparison.

62. Form of arms of sternum VIII (Figures 58-59, 62-63).

0 . Apicolateral margin of arms of various shapes, generally convex in outline.

1. Apicolateral margin of arms broadly emarginate.

Among weevils in general and in most Bagous, the arms of sternum VIII of females are generally laterally convex (outer margin). In some species the outer margin is emarginate, giving each arm a rather triangular shape, and we consider this apomorphic. Basis for polarity: in-group and out-group comparison.

This occurs in a number of Japanese species that appear to be related somewhat but of unclear relationship. On the basis of this character it is likely that B. subcordatus belongs to the B. bipunctatus group. Conversely, B. lewisi, B. subvittatus and B. tuberculosus do not possess this character and therefore probably do not belong to this group. Possibly this character is synapomorphic for the B. bipunctatus group, exclusive of B. ryukyuensis; females of B. occultus are not known and the state is assumed on the basis of character correlation. 
66. Divergence of apademes (Figure 54).

0 . Apodemes parallel, subparallel or contiguous for most of length.

1. Apodemes moderately divergent, broadly contiguous in basal half.

Typically among species of Bagous and weevils in general, the apodemes of the female stemite VIII are narrowly separated basally to subapically, where they diverge to some degree, typically quite broadly., and generally extend markedly toward the lateral margin of the plate of sternum VIII. The appearance is therefore generally of a single rod-like stucture, which bifurcates apically. In a number of unrelated species or groups of species, the apodemes are moderately cleft toward the base, and we consider this apomorphic. Basis for polarity: in-group and outgroup comparison.

This character is possessed by several unrelated taxa, among Japanese Bagous by $B$ bipunctatus and $B$. youngi. Presently the character does not resolve relationships, but does seem to suggest relationships among some non-Japanese species.

70. Shape of spermathecal nodulus (Figures 58-59, 62-63).

0 . Nodulus of various shapes.

1. Nodulus somewhat produced near spermathecal duct insertion, together with ramus forming somewhat triangular region.

Among Bagous and weevils in general, the spermathecal nodulus is generally rather convex, often wrinkled, but seldom produced in a marked way. Among most species of the $B$. bi punctatus group (exclusive of B. ryukyuensis), the nodulus is rather distinctly produced, giving the spermatheca a rather triangular shape, and we consider this condition apomorphic. The female of B.occultus is not known, but the character is assumed based on character correlation. Basis for polarity: in-group and out-group comparison.

72. Shape of apical margin of female pygidium. (Figure 56, e).

0 . Apical margin of pygidium rounded or truncate.

1. Apical margin of pygidium deeply emarginate.

Among species of Bagous the pygidium is generally truncate or very slightly emarginate. We therefore consider the deeply emarginate pygidium apomorphic. Among Japanese Bagous this state occurs only in B. fritodes. Basis for polarity: in-group comparison.

\section{EXTERNAL STRUCTURE.}

\section{Body shape.}

0. Body elongate-oval.

1. Body elongate-cylindrical.

Weevils in general are elongate-oval in body shape, as are most Bagous, also. Therefore we consider this condition plesiomorphic. Basis for polarity: in-group and out-group comparison.

Some species of Bagous are relatively cylindrical and elongate. This is particularly so for certain European species, and similarly the B. longulus group, though the former are much more cylindrical. One Japanese species, B. buckinghami, is relatively cylindrical, but is unrelated to any of these. Clearly these occurrences are homoplastic. 
74. Body shape (Character 31 in O'Brien \& Askevold, 1992) (Figs. 1-4 in O’Brien et al., 1994).

0 . Body elongate-oval.

1. Body short and broad-oval.

Weevils in general are elongate-oval in body shape, as are most Bagous, also. Therefore we consider this condition plesiomorphic. Basis for polarity: in-group and out-group comparison.

Among species of Bagous, a group of species is unique in their very short broad-oval shape that is produced by marked reduction of post-declivital body length (i.e., virtually no caudal prolongation as is typical of the majority of weevils). This character state defines the $B$. pygmaeus group, whose members use Azolla as host plants.

75. Size (Character 32 in O'Brien \& Askevold, 1992).

0 . Medium-sized species--2 to $4 \mathrm{~mm}$.

1. Large species--4mm. or larger.

Among species of Bagous, a group of species is unique in their large size, and this condition is considered apomorphic. Basis for polarity: in-group comparison.

Several other species from other geographic regions, including two from India, one from Thailand, and at least one from Africa, are also large. This synapomorphy defines an extraordinary group which is represented among taxa considered here only by $\mathbf{B}$. natator.

76. Size (Character 33 in O’Brien \& Askevold, 1992) (Figs. 1-4 in O'Brien et al., 1994).

0 . Medium-sized species--2 to $4 \mathrm{~mm}$.

1. Small species--less than $2 \mathrm{~mm}$.

Among species of Bagous, a group of species is unique in their diminutive size, and this is considered apomorphic. This character state defines the B. pygmaeus group, whose members use Azolla as host plants. Basis for polarity: in-group comparison.

77. Scale structure (Character 34 in O'Brien \& Askevold, 1992).

0 . Scales flat, unmodified, not pitted.

1. Scales subgranulate to granulate, moderately to strongly, distinctly pitted.

2. Scales smooth and shiny, with at most a very fine pit.

Weevils in general are either glabrous, pubescent or scaled; many stenopelmines have secretory scales that are similar to those of Bagous, but these weevils do not appear to be related even remotely to Bagous. Secretory scales are clearly apomorphic in these groups as an adaptation to aquatic life. [Note that there are secretory scales in some groups of terrestrial weevils living in arid regions.1 Basis for polarity: out-group comparison.

All members of Bagous possess a specialized scale structure, covering almost the entire body dorsally and ventrally, exclusive of areas of articulation. Scales of Bagous are secretory, producing a waterproof coating that frequently covers entire specimens and obscures structures. Similar specialized scales appear to have evolved independently among many unrelated groups of aquatic weevils. At present, we know of no other genus that possesses the same type of secretory scales as does Bagous, and therefore consider this character synapomorphic for the genus.

In some species, including B. laevigatus, B.affinis (India), B. argillaceus (Europe) and other species known from China, Africa and North America, the scales are further modified and are smooth and shiny, with at most a very fine central pit $\left(77^{2}\right)$. This state does not occur among 
any of the species under consideration here, and is therefore not discussed further.

78. Length of rostrum (Character 35 in O'Brien \& Askevold, 1992).

0 . Rostrum long, in most specimens more than than 0.85 times (male), or 0.90 times (female) as long as prothorax.

1. Rostrum short, in most specimens less than 0.85 times (male), or 0.90 times (female) as long as prothorax.

2. Rostrum elongate, at least as long as prothorax.

Among weevils generally, the length of the rostrum is greater than these values. Therefore we consider the longer rostrum to be the plesiomorphic condition. Basis for polarity: in-group and out-group comparison.

Among species of Bagous, especially in females, the rostrum is less than $0.90\left(\sigma^{*}\right)$ or 0.85 (P) times the pronotal length. This condition defines the majority of the genus, even in taxa that are most plesiomorphic on the basis of other characters (especially the B.crispus group). Therefore the shortened rostrum must be considered synapomorphic for the genus. A number of species or groups of species within the genus, however, have a more elongate rostrum, notably species of the B. pygmaeus and B. humeridens groups. As evidenced by other characters, these lineages have apparently undergone reversal, and are therefore coded $78^{2}$ in accordance with methods of in transitum analysis.

79. Median carina of rostrum (Figure 35, ac).

0 . Rostrum lacking median longitudinal carina.

1. Rostrum with median longitudinal carina.

Rostra1 carinae are common among weevils, but we do not think they are part of the Bagous ground plan. Most species of Bagous lack carinae on the rostrum, save those which are generally present above the suprascrobal sulcus. A few species possess a median carina distally, which we consider apomorphic. This character occurs in widely unrelated species or groups of species. Among Japanese and Australian Bagous, only B. occultus has this carina. Basis for polarity: in-group and out-group comparison.

80. Suprascrobal sulcus of rostrum (Character 36 in O'Brien \& Askevold, 1992) (Figure 35, ss).

0 . Rostrum lacking lateral sulcus above scrobe.

1. Rostrum with distinct, well-developed, lateral sulcus above scrobe. Sulcus may be poorly developed, evidenced only by a carina of scrobe, basally.

2. Rostrum with basolateral sulcus obliterated.

Weevils in general lack an evident suprascrobal groove, but similar sulci have evolved independently in unrealted groups, i.e. stenopelmines, some anthonomines, and others. Most species of Bagous possess some sort of longitudinal sulcus above the antennal scrobe, generally delimited dorsally by a poorly to well-developed carina or at least a longitudinal angulation. We therefore consider presence of a suprascrobal sulcus synapomorphic for Bagous, with subsequent losses among various, unrelated lineages. Basis for polarity: in-group and out-group comparison.

On the basis of character correlation, it is clear that secondary losses of the sulcus have occurred. This condition occurs in widely unrelated taxa, as evidenced by other characters. Because these instances are clearly secondary, we assign the state $80^{2}$ to these taxa. Such 
assignment is strictly done a posteriori, in accordance with methods of in transitum analysis.

\section{Rostral angulation.}

0. Rostrum with dorsal surface more or less uniformly convex from frons to apex.

1. Rostrum with dorsal surface at point of antennal insertion abruptly angulate, with distal surface flat.

Among weevils in general and the majority of Bagous, the rostrum is more or less uniformly arcuate toward the apex, or at least not abruptly declivous. Some species possess a rostrum which is abruptly angulate at the point of the antennal insertion, producing a rather shiny, glabrous area at this angle, and this is clearly apomorphic. Basis for polarity: in-group and outgroup comparison.

This character is almost exclusive to and synapomorphic for a group of species which we refer to as the B. Iongulus group, which is most species rich in Africa, but which has one species in India, B. nymphaeae One Japanese species, B. tuberculosus, also possesses a rather angulate rostrum. Development of this angulation is rather different, and other characters defining the $B$. longulus group are lacking, so we are confident that B. tuberculosus does not belong to this group.

83. Insertion of antennae (Character 38 in O'Brien \& Askevold, 1992).

0 . Antennae inserted at about midlength of rostrum.

1. Antennae inserted toward apex of rostrum.

2. Antennae inserted subbasally.

3. Antennae inserted near middle.

Typically among weevils, the antennae are inserted on the rostrum at about midiength, and we consider this the plesiomorphic condition. Most Bagous (with exceptions noted here), have the antennae inserted toward the rostral apex, and we consider this state synapomorphic for the genus $\left(83^{1}\right)$. The species we consider most plesiomorphic in the genus (i.e, species of the B. crispus group) do not have the antennae inserted markedly toward the rostral apex, but the antennae are distinctly subapical (83'). This condition therefore is considered synapomorphic for the genus. Basis for polarity: in-group and out-group comparison.

We recognize two conditions that are derived from the subapical antennal insertion. In a few species the antennae are inserted basally; the apical portion of the rostrum is therefore relatively long $\left(83^{2}\right)$. This extreme condition is known in only a few species which comprise the highly derived $\mathrm{B}$. trapae group, for which we consider this state synapomorphic.

In some species, the antennae are inserted at the middle $\left(83^{3}\right): B$. darenciensis (especially females), B. utriculariae, and two species of the B. hydrillae group. Some other species of the B. pygmaeus group have a typical antenna1 insertion, while some are like B. darenciensis. On the basis of character correlation, it is clear that the condition in these species represents secondary reversal. Because these instances are clearly secondary, we assign the state $83^{3}$ to these taxa. Such assignment is done strictly a posteriori, in accordance with methods of in transitum analysis. For final analysis, a stepmatrix was used to define the relationship of states of this character, for it is a "partially ordered" character with the relationship $0(1(2,3))$ of its states. 
84. Rostrum (Figure 35).

0 . Rostrum transversely flat or convex.

1. Rostrum apically bisulcate, with longitudinal sulcus on either side of raised, median carina.

Rostral carinae and sulci are common among weevils, but we do not think they form part of the Bagous ground plan. Most species of Bagous lack subapical sulci on the rostrum. We therefore consider this condition plesiomorphic. Basis for polarity: in-group and out-group comparison,

This character occurs in unrelated species or groups of species. Among taxa considered here, only B. occultus has this pair of sulci, which are short and indistinct. The sulci are much better developed in several North American species, which are unrelated to B. occultus.

92. Prosternal-postocular lobe area.

0. Postocular lobe ventrally indistinct, not raised, not forming discontinuity with anterior prosternal margin.

1. Postocular lobe ventrally distinct, somewhat to markedly raised, forming discontinuity with anterior prosternal margin and with anterior point of lateral margin of sulcus.

Various groups of weevils possess postocular lobes, but lack of them is plesiomorphic, and we therefore consider that a more poorly developed ventral portion of the ocular lobes probably also is plesiomorphic. Basis for polarity: out-group comparison.

In almost all Bagous, postocular lobes extend toward the prosternum and form the anteriormost part of the prostemal sulcus. Therefore, the sulcus is comprised of two components, which are distinguishable by a discontinuity or notch between them. Generally, the better developed the prostemal sulcus, the more distinct the ventral lobe portion of it is (that is, more distinctly raised). When the ocular lobes are well-developed ventrally, they form a marked discontinuity with the anterior prosternal margin, and we consider this apomorphic.

Among Bagous, generally only the plesiomorphic members have a poorly developed prosternal sulcus (except $B$. (Ephimeropus) geniculatus Hochhut) (European) and an undescribed species from India assignable to $B$. (Ephimeropus). They also have a poorly developed ocular lobe portion of the sulcus, and therefore lack a marked discontinuity of the prosternal margin. This condition is found in members of the B. crispus and B. pygmaeus groups, and the derived condition is synapomorphic for the genus exclusive of these two groups. The position of these two species of B. (Ephimeropus) is unclear because they are highly derived in other characters, while B. (E.) petro Herbst (European) has derived prosternal structure.

94. Basal carina of pronotum.

0 . Pronotum lacking carinate basal margin.

1. Pronotum with indistinctly to distinctly carinate basal margin across middle one-fourth to one-half.

Among weevils in general, and in the majority of Bagous, the pronotum is not marginate basally. Presence of a basal margin is therefore apomorphic. Basis for polarity: in-group and out-group comparison.

Within Bagous, various taxa possessing a basal margin are unrelated, as evidenced by character correlation. Among Japanese Bagous, this is the case with the possible exception of two species known only from females; B. lewisi and B. subvittatus have this apomorphy, but in 
the absence of male specimens, a relationship is unsupported. The basal margin when present varies in development, from indistinct to prominent.

96. Shape of pronotal disc (Character 39 in O'Brien \& Askevold, 1992).

0 . Pronotum with disc medially flat (with median sulcus or not).

1. Pronotum with disc moderately strongly transversely convex.

Among many weevil groups, and among most Bagous, the pronotal disc is somewhat flattened medially, not uniformly convex. We therefore consider this state apomorphic. Basis for polarity: in-group and out-group comparison.

Among a few groups of species of Bagous, the pronotal disc is narrowed and markedly transversely convex (and also lacks a median sulcus). We consider this strongly convex condition synapomorphic for the B. pygmaeus group and independently derived in the B. humeridens group.

97. Longitudinal pronotal sulcus (Character 40 in O'Brien \& Askevold, 1992).

0 . Pronotum lacking median longitudinal sulcus or impression.

1. Pronotum with complete median longitudinal sulcus or impression.

2. Pronotum with sulcus reduced to posterior and anterior impressions only.

3. Pronotum with sulcus obliterated.

A dorsal median sulcus is not usual among weevils, therefore presence of a sulcus is considered apomorphic. Basis for polarity: in-group and out-group comparison.

Most Bagous have a pronotum that is sulcate in some way along the dorsal midline, and the disc is somewhat flattened, not uniformly convex. We consider this condition synapomorphic for a subset of the genus, excluding only species of the B. crisps and B. pygmaeus groups. Lack of a median sulcus also occurs in several other taxa or groups of more highly derived taxa of Bagous, but these must be secondary reversals.

Two states appear to be derived independently from $97^{1}$. A few species have the sulcus restricted to posterior and anterior impressions, but presently we consider this a secondary reduction; none of the species under consideration here possess this state. A nonsulcate condition occurs in two apparently closely related groups of species, for which we consider this a secondary reversal; we coded these reversals, in accordance with methods of in transitum analysis as 97'. This state supports grouping of the B. humeridens and B. apicalis groups as sister groups

In future analyses which include taxa possessing $97^{2}$, a stepmatrix will be needed to define the relationship $0(1(2,3))$ of states, for it is a "partially ordered" character.

103. Prosternal sulcus (Character 41 in O'Brien \& Askevold, 1992).

0 . Prosternum more or less convex or flattened, without median, laterally margined sulcus.

1. Prosternum with scarcely evident sulcus, lateral margins more or less parallel and weakly raised.

2. Prosternum moderately to deeply sulcate, with moderately to markedly acute, longitudinally arcuate to biangulate lateral margins.

Typically among weevils, the prostemum between and anterad of the procoxae is not modified as a sulcus into which the antennae and rostrum fit in repose (though this does occur in severeal groups). Therefore we regard lack of a sulcus as the plesiomorphic condition. Basis for polarity: in-group and out-group comparison. 
Some sort of sulcus, at least scarcely evident, is possessed by almost all Bagous, and therefore we consider this a synapomorphy for the genus (103'). This state is retained by members of the B. crispus and B. pygmaeus groups, and B. josephi (monobasic) group. We consider $103^{2}$ synapomorphic for all Bngous exclusive of these species groups.

Bagous (Ephimeropus) geniaulatus and an undescribed species from India assignable to B. (Ephimeropus) possess no sulcus. They possess a transverse ridge just before the procoxae, but the prostemum is somewhat impressed but not longitudinally sulcate in front of this process; this is a loss of the normal sulcus because other, apparently closely related species e.g. B. (Ephimeropus) petro do possess a well-developed sulcus.

104. Margins of prosternal sulcus (Character 42 in O'Brien \& Askevold, 1992).

0 . Side margins of prosternal sulcus (in lateral view) not clearly raised.

1. Side margins of prosternal sulcus (in lateral view) sharply raised, markedly rounded or subacute, just in front of coxae.

2. Side margins of prosternal sulcus (in lateral view) sharply raised, strongly ventrally acute, just in front of coxae.

3. Side margins of prosternal sulcus (in lateral view) strongly acute and projecting posterad over procoxae.

As in the preceding character (103), the prostemum between and anterad of the procoxae is not modified as a sulcus among weevils in general, nor is this sulcus defined posterolaterally by a distinctly raised margin (lateral view). We therefore regard an unraised margin defining this sulcus as plesiomorphic. Basis for polarity: in-group and out-group comparison.

Some sort of distinctly raised (104') margin in front of the procoxae is possessed by most Bagous, and we therefore consider this state synapomorphic for Bagous exclusive of the B. crispus and B. pygmaeus groups.

Previously (1992), we considered the acutely raised margin $\left(104^{2}\right)$ synapomorphic for the B. humeridens + B. apicalis groups + all species possessing a dorsal process, with the condition found in B. natator being a reversal (104'). With addition of Japanese species, this is no longer the most plausible explanation. Rather, it appears that $104^{2}$ is developed independently in several unrelated lineages, though this is still synapomorphic for some groups of species. We consider $104^{2}$ to be in support of the relationship of the B. humeridens + B. apicalis groups, and the $B$. addaidae + B. trapae groups. A reversal must nonethless be invoked to explain B. natator.

Among Australian species, the B. addaidae group has the margin prominently projecting posterad over the procoxae (104'). A similar state also occurs in species of the B. longulus group, but the process is strongly medially directed; these groups are quite unrelated, however, because the B. longulus group lacks a dorsal process.

In future analyses including taxa possessing $104^{3}$, a step matrix will be needed to define the relationship $0(1(2,3))$ of states, for it is only a "partially ordered" character.

106. Arrangement of elytral scales (Character 43 in O'Brien \& Askevold, 1992).

0 . Elytra with scales irregularly arranged, each interval with more than two rows of tightly fitting scales across each interval.

1. Elytra with scales arranged in regular pairs, side by side, each interval with two, individually distinct rows of round scales across each interval.

Among many groups of weevils, when elytral scales are present, they are generally 
irregularly, if densely arranged. Among Bagous, elytral scales are generally irregularly arranged, tightly fitting, and in more than 2 rows in number over most of the length of most or all intervals. This state is therefore considered plesiomorphic. Basis for polarity: in-group and outgroup comparison.

One group of species of Bagous possesses a peculiar arrangement of scales in two discrete rows on all intervals. Scales are placed in regular pairs, side by side, no more than 2 in number across the interval. We consider this arrangement synapomorphic for the B. pygmaeus group.

107. Shape of elytral humerus (Character 44 in O'Brien \& Askevold, 1992).

0 . Elytra with humeri subquadrately rounded.

1. Elytra with humeri obliquely angulate, not produced.

2. Elytra with humeri obliquely angulate, weakly to moderately, not acutely produced.

3. Elytra with humeri obliquely angulate, acutely laterally produced.

Typically among weevils with hind wings, the humerus is subquadrately rounded, not produced in some way; therefore we consider this state plesiomorphic. Basis for polarity: out-group comparison.

Almost all Bagous have a modified humeral angle, exclusive of species of the B.crispus group and the B. pygmaeus group. The angulate but not produced humerus (107') we therefore consider synapomorphic for species of the genus exclusive of these groups. Some other species or groups of species of the genus have the humerus weakly to moderately, but not acutely, produced $\left(107^{2}\right)$; presently this state supports grouping the $B$. humeridens + B. apicalis groups, B. trapae +B. adelaidae groups, and the B. hydrillac group. Species of the B. humeridens group possess an acutely, laterally produced humerus $\left(107^{3}\right)$, which we consider synapomorphic for this group.

110. Elytral intervals (Character 45 in O'Brien \& Askevold, 1992).

0 . Elytra with all intervals flat.

1. Elytra with odd-numbered intervals raised.

2. Elytra with all intervals flat.

Most weevils have all intervals flat and we consider this condition plesiomorphic. Among Bugous, raised odd-numbered intervals therefore is considered derived. Basis for polarity: out-group comparison.

Previously (1992), we did not find that this character resolved relationships, but that among Australian species, $110^{1}$ supported monophyly of all species exclusive of B. clarenciensis (with reversal in B. dostine). With addition of Japanese taxa, it appears more probable that convexity of elytral intervals is synapomorphic for the genus, with multiple independent reversals.

On the basis of character correlation, reversal in some species can be identified. Among Japanese species, B. clarenciensis and B.buckinghami possess all intervals flat, but related taxa are 110'; therefore, we assign these species the state $110^{2}$, done a posteriori, in accordance with methods of in transitum analysis.

115. Antedeclivital callus of third interval (Character 46 in O'Brien \& Askevold, 1992).

0 . Elytra without tubercle on third interval just before declivity.

1. Elytra with, weakly to moderately developed tubercle on third interval just before declivity. 
2. Elytra with tubercle of third interval extremely large, projecting.

Weevils in general, as well as most species of Bagous, do not possess an antedeclivital callus on the third interval, so we conclude that presence of such a callus is apomorphic. Various unrelated species or groups of species possess a small to quite prominent antedeclivital callosity. Basis for polarity: out-group comparison.

Unrelated species possess this character: B.apicalis, B. trapae group, $B$. dubius (in $B$ hydrillae group), B. kagiashi, and B. proprius. Bagous tuberculosus and B. lewisi, known only from female specimens, could be placed near $B$. proprius on the basis of this character, but other characters conflict, and there are no supporting genital characters.

116. Declivital callus of fifth interval (Character 47 in O'Brien \& Askevold, 1992).

0 . Elytra without declivital callus.

1. Elytra with obtuse, rounded to subquadrate, poorly to well-developed, small but distinct, declivital callus on fifth interval.

2. Elytra with large, subacute to acute, declivital callus on fifth interval, extending beyond side margin of elytra.

Weevils generally do not have a callosity on the fifth interval. The most plesiomorphic members of Bagous (as indicated by other characters) lack a callus also, so we conclude that presence of a callus is apomorphic. Basis for polarity: in-group and out-group comparison.

Most species of the genus possess a callus on the 5th interval, exclusive of the B. crispus and $B$. pygmaeus groups; we conclude that this character is synapomorphic for the genus exclusive of these groups. Other taxa that lack a callus are quite unrelated (B. femoralis O'Brien, among Australian species), and these must be secondary losses.

In some species, this callus is greatly enlarged and projects laterally $\left(116^{2}\right)$, occurring in species of the $B$. humeridens group, an undescribed species in the B.apicalis group, most species in the B. trapae group, and B. tuberculosus. These groups are not closely related to one another, as evidenced by other characters. However, it could be argued that the $B$. humeridens and $B$. apicalis groups share this synapomorphy, with one reversal.

119. Tibial denticles (Character 48 in O'Brien \& Askevold, 1992).

0 . Tibiae with prominent, stout denticles.

1. Tibiae with ventral surface simple, with denticles greatly reduced or absent, especially on metatibiae.

Most species of Bagous, and many weevils in general, possess prominent denticles on the inner margin of the tibiae, each set with a prominent seta or bristle. Within Bagous this condition is found in the most primitive species, the $B$. crispus group, among various other unrelated species, and among a large group of the most highly derived species. Species possessing these stout denticles also typically have a prominent seta associated with each denticle. Therefore we assess this condition as plesiomorphic. Basis for polarity: in-group and our-group comparison.

Several groups of species seem to share loss or marked reduction of these denticles: the $B$ pygmaeus group, $B$. josephi (monobasic group), the $B$ hydrillae group (including relatively primitive species of the group such as B.pauxillulus), and among Japanese species, B. proprius, B. tuberculosus and B. subvittatus. 
121. Swimming hairs of tibiae (Character 49 in O'Brien \& Askevold, 1992).

0 . Tibiae with bristles of inner margin of moderate length, not longer than diameter of tibia.

1. Tibiae with long fine swimming hairs, many much longer than diameter of tibia; long, longitudinally adpressed setae also present on lateral surfaces.

Typically among weevils, and among about $50 \%$ of species of Bagous studied, setae of the inner tibial margin are of moderate length, i.e. about as long as tibial diameter. This state is therefore assessed as plesiomorphic. Basis for polarity: in-group and out-group comparison.

In some species, tibial bristles are greatly elongated to form long, slender swimming hairs (not unlike those found in water beetles). This condition is clearly derived, possessed by two groups of species. We consider this a synapmorphy for the B. trapae group. Another group of species also possess such swimming hairs, e.g. an undescribed Indian species of B. (Ephimeropus), as do some other species presently assigned to this subgenus but of undetermined relationship in the genus, but these do not possess a dorsal process of the median lobe, and therefore are unrelated to the B. trapae group.

122. Length of tibial bristles (Character 50 in O'Brien \& Askevold, 1992).

0 . Tibiae with bristles on inner margin of moderate length, setae not longer than diameter of tibia.

1. Tibiae without prominent setae or bristles, or if evident then very short and relatively inconspicuous.

Typically among weevils, and among about $50 \%$ of species of Bagous studied, setae of the inner tibial margin are of moderate length, i.e. about as long as tibial diameter. This state is therefore assessed as plesiomorphic. Basis for polarity: in-group and out-group comparison.

Two derived conditions of tibial seta length are found in Bagous, increase in length as swimming hairs (see character 121) and reduction to complete loss. Among Australian species, most members of the $B$. hydrillae group have markedly reduced tibia1 setae. We concluded this character is synapomorphic for a portion of the B. hydrillae group, independently reduced in $B$. propinquus. Most members of the B. pygmaeus group taxa are $122^{1}$, while B. clarenciensis is $122^{\circ}$. Among Japanese species, this loss occurs in B. proprius, B. fractus, B. occultus, B. minor + B. pygmaeodes, B. lewisi, B. suhvittatus, and B. tuberculosus. Thus it appears that, as with several other external characters, tibial vestiture is reduced independently within and among unrelated species groups.

123. Shape of tibia1 apex (Character 51 in O'Brien \& Askevold, 1992).

0 . Tibiae, especially hind tibiae, with dorsal margin straight or nearly so toward apex (in lateral view).

1. Tibiae with dorsal margin slightly to moderately arcuate.

2. Tibiae strongly arcuate toward apex.

3. Tibiae very strongly arcuate towards apex (all tibiae thus), uncus directed inwards and forming an angle less than 90 degrees with basal axis of tibia.

Among the most primitive members of Bagous and many weevils in general, the dorsal tibial margin is more or less straight toward the apex. The tibiae therefore even broaden somewhat at the extreme apex, because the ventral margin is arcuate apically. We therefore assess this state as plesiomorphic. From this state we recognize three serially derived conditions. 
Basis for polarity: in-group and out-group comparison.

Among Bagous, the plesiomorphic condition is retained by species of the B.crispus group. A few species, such as B. laevigatus (India) (and several species related to it), also have an almost straight dorsal margin. We distinguish three categories of tibial curvature; because of this curvature, the tibia slightly narrows apically, generally giving the tibia a rather slender appearance. Therefore also, the angle formed by the uncus with the tibial axis becomes less obtuse, even acute in some groups. It appears that tibial curvature is highly homoplastic, but marked curvature serves to define various, independent groups. In some species, the metatibiae are slightly less arcuate than are the pro- and meso-tibiae. Many species, such as species of the B. pygmaeus, B. humeridens and B. apicalis groups and some members of the large group of species possessing a dorsal process of the median lobe, have the tibial apex only slightly to moderately arcuate, with the uncus at most forming a $90^{\circ}$ angle (123'). This state we consider synapomorphic for Bagous exclusive of the B. crispus group.

Other groups of species have the tibial apices more markedly arcuate, with the uncus forming an angle slightly less than $90^{\prime \prime}\left(123^{2}\right)$. Many members of the B. hydrillae group and B. natator possess this state. We distinguish a third state, of greater curvature, with the uncus forming a distinctly acute angle (123'); no species of the faunas presently under consideration possess this state, but it is exclusive to most members of the B. trapae group.

125. Shape of tarsomeres (Character 52 in O'Brien \& Askevold, 1992) (Figures 136-138).

0 . Tarsi broad, with tarsomere 3 distinctly bilobed.

1. Tarsi short, with tarsomere 3 broadly cordate to subcordate.

2. Tarsi moderately short-sublinear to elongate-sublinear, tarsomeres moderately broadened apically, and/or tarsomere 3 slightly broader than 2 .

3. Tarsi elongate-linear, tarsomeres all slender, equal in width.

Weevils typically have the third tarsomere distinctly bilobed, and we therefore consider this the plesiomorphic condition. Among Bagous, there appear to be multiple, independent trends to reduction of tarsomere width (using principally the third tarsomere as a measure of this). We recognize three categories of reduction of tarsomere width. Basis for polarity: in-group and out-group comparison.

All Bagous have some reduction of lobes of tarsomere 3, at most being broadly cordate (12.5') (as in Fig. 36). We consider this condition synapomorphic for the genus, retained by members of the B. crispus group (though there are some reversals). Various unrelated taxa also have this state but they are not necessarily primitive within their respective groups. For example, occurrences of this state $\left(125^{1}\right)$, in B. ryukyuensis (which is plesiomorphic in its group), $B$. subcordatus and B. bipunctatus (derived in their group) and B. femoralis (Australia) must be considered reversals on the basis of character correlation, and because other, related members have a more derived tarsal condition.

We recognize an intermediate category (which, for convenience, is really a range), in which the tarsi are sublinear $\left(125^{2}\right)$, each tarsomere slightly broadened subapically, and tarsomere 3 is only slightly broader than 2 . The overall tarsal length varies from short to elongate (e.g. Fig. 38). This condition is achieved independently in many lineages.

Certain highly derived Bagous species possess very slender, completely linear tarsi; in these each tarsomere is more or less cylindrical (125') (e.g. Fig. 37). This state occurs in quite unrelated species, and even sister species may have quite different tarsal structure (e.g. B blyxae 
is state $125^{3}$, but $B$. blyxodes and B.matthewsi are state $125^{2}$ ). One group of very highly derived species, the B. trapae group, possess this state, which we consider synapomorphic for the group. Among other species groups, B. occiduus and B. blyxae (B. hydrillae group), B. humeridens group (India) and B. apicalis group also possess $125^{3}$, and B. buckinghami possesses this state.

126. Pubescence of tarsi (Character 53 in O'Brien \& Askevold, 1992).

0 . Third tarsomere clothed beneath with dense, erect pubescence.

1. Third tarsomere clothed beneath with fine to coarse, dense, recumbent to subrecumbent pubescence.

2. Third tarsomere sub-glabrous beneath, with few long setae.

Weevils typically have pubescence that is dense and erect on the underside of tarsomeres; we therefore consider this state plesiomorphic. Basis for polarity: in-group and out-group comparison.

All Bagous have ventral pubescence of tarsi that is fine to coarse and at least subrecumbent $\left(126^{\prime}\right)$, and we consider this state synapomorphic for the genus. One group of very highly derived species (B. trapae group) possess tarsal pubescence that is markedly elongate and recumbent, and rather sparse $\left(126^{2}\right)$. We consider this state synapomorphic for this group of species.

\section{RESULTS AND DISCUSSION.}

\section{MANUAL RECONSTRUCTION OF RELATIONSHIPS.}

Japanese species only -- Our hypothesis of relative relationships of Japanese Bagous according to manual reconstruction is presented in Fig. 1. The manual reconstruction represents a compromise between arrxnging taxa most parsimoniously and most confidently. Japanese members of Bugous fall into 3 principal lineages, the B. pygmaeus group, the B. bipunctatus group, and a diverse assemblage of species (6 species groups) which possess a dorsal process of the median lobe. This general arrangement mirrors closely that found for the Australian Bagous, with the B. pygmaeus group being basal, and the B. josephi and B. hydrillae groups being intermediate in position between the former group and the assemblage of species groups with a dorsal process. Here the B. pygmaeus group is again basal, and the assemblage of taxa possessing a dorsal process is most highly derived, and the B. biptunctatus group is intermediate in position. We are confident that these three main lineages are well founded, but relationships of taxa within these lineages are not clear. Details about each species group are discussed below.

Japanese and Australian species -- Species groups previously defined for Australian Bagous were collapsed into single terminal taxa (character states assigned according to Methods) the B. hydrillue-group and $B$. udeluidae-group. Manual reconstruction (Fig. 2) of the combined species produced a tree that mirrors closely that for the Japanese Bagous alone (Fig. 1), and for the Australian Bagous alone, as in O'Brien and Askevold (1992). Relationships mostly are well supported, but two groupings remain unresolved (two polytomies). Exclusion of B.josephi from the remaining Bagous is weakly supported by one character $\left(103^{2}\right)$; while this is consistent with analysis of the Australian Bagous alone, the relationship is not supported in all analyses that 
include the Japanese taxa.

This reconstruction differs somewhat from the analysis of Australian species; it now appears more reasonable to place $B$. utriculariae and $B$. apicalis as sister lineages (representing distinct species groups), contrasting with O'Brien \& Askevold (1992). The large number of characters that occur on terminal lineages, apparent autapomorphies, mostly are characters that define the species groups that are represented by the taxa in this analysis (a geographic subset). This is especially so of B. utriculariae, B. apicalis, B. proprius and B. natator. In the present analysis, B. fractus, B. huckinghami and B. rotundatus are not related obviously to any taxa that we know of. Therefore, they are tentatively assigned to separate, monobasic species groups with the expectation that other members will be found, In contrast, while B. youngi and B. fritodes are apparently most closely related to one another among the taxa under consideration, we are familiar with extralimital taxa that are very closely related to each of them and which are members of the same groups.

\section{RECONSTRUCTION OF RELATIONSHIPS USING PAUP.}

Japanese species only -- Analysis of Japanese Bagous alone, without weighting characters, produced 7 trees with a high degree of concordance among them (B. tuberculosus, B. lewisi and B. subvittutus were excluded). The same trees were generated using heuristic and branch and bound algorithims. Relative relationships of Japanese Bagous according to PAUP reconstruction are depicted in Fig. 3 (strict consensus tree). This tree agrees closely with the manual tree (Fig. 1) except for the lineage that includes B. fractus, B. buckinghami, B. rotundatus, B. youngi and B. fritodes. With three characters weighted (14 and 17), resolution among these taxa is improved (Fig. 4). The level of resolution is high in comparison with the level of homoplasy that was found previously in study of Australian Bagous.

Japanese and Australian species -- Analysis of Australian and Japanese Bagous combined required excessive time for analysis. Analysis was aborted when over 3000 trees had been saved because no appreciable difference in tree topology was generated regardless of duration of analysis. Terminating analysis at 1400 trees provided results that were not different from 3000 trees, etc., so it was unproductive to continue analysis to completion considering memory limitations and duration.

First, analysis was done using characters entirely unweighted (Fig. 5, strict consensus tree). Certain species groups are clearly monophyletic: B. pygmaeus group, B. utriculariae + B. apicalis lineage, B. adel aidae group, B. bipunctatus group, and most of the B. hydrillae group (excluding B. pauxillulus, which lacks certain characters possessed by the rest of the group). While a strict consensus tree shows only the branching pattern common to all trees, it is also uninformative about what arrangement is common to most trees; majority-rule consensus trees show this. This latter information is intuitively employed in manual reconstruction. A majority-rule tree shows branch frequency among the trees generated (Fig. 6). From this, it can be seen that the majority of equally-parsimonius trees support an arrangement that is very similar to the overall manual reconstructions, and to the analysis using weighted characters. Results, even with unweighted characters, support theoretically the method of collapsing known species groups into single lineages for simplification of analysis. In addition, while the species groups themselves are supported, it is clear that relationships within these groups are not well resolved, and that this 
lack of resolution accounts for the bulk of analytical time, to no fruitful end. This is important to demonstrate, because in future analyses, the data set on world Bagous will become extremely large. It will be essential to simplify analysis by species group reduction (through collapsing) because of the homoplasy within these groups.

Second, analysis was done separating external and genital characters to examine their relative effect on results. The species B. tuberculosus, B. lewisi and B. subvittatus were included in the external character analysis because external characters are available for these taxa. Using external characters only, there is extremely high lack of resolution in the strict consensus tree (Fig. 7), indicating that there is a high level of homoplasy. Use of external characters only seems to resolve well the basal branch sequences, but not higher branch sequences. The strict consensus tree shows support for the B. pygmaeus group, lower separation of B. josephi from the rest of the genus, and monophyly of a few other groups, as above. However, according to the majority-rule consensus tree (Fig. 8), all of the B. hydrillae group is supported as monophyletic in most trees (with $B$ tuberculosus included!). All trees support grouping of B. subvittutus, B. proprius and B. lewisi, but this is almost certainly incorrect.

Analysis of genital characters alone was done to examine their relative effect on results. Use of genital characters only seems to resolve well the middle range branch sequences that define species groups, but not lower branch sequences, according to the strict consensus tree (Fig. 9). This difference between external and genital characters in ability to resolve relationships supports weighting certain genital characters highly in order to enforce particular relationships. A weighted analysis, of course, refines better the relationships among larger polytomies. In contrast, certain relationships, such as that of the B. pygmaeus group, is entirely unsupported by genital characters; in fact, the majority of trees separate B. clarenciensis widely from the two Japanese species, B. minor and B. pymaeodes (Fig. 10, majority-rule consensus tree). Overall, the level of resolution obtained, and the lesser degree of homoplasy, suggests that genital characters are more conservative and less prone to reversal in particular.

Third, analysis including all taxa and all characters, and weighting characters 3,14 and 17 highly, generated results that are essentially like manual reconstruction. The combined effect of external characters resolving lower branches, and genital characters resolving midrange branches is to produce a much more highly resolved tree. A strict consensus tree (Fig. 11) still suggests considerable lack of resolution concerning placement of $B$. proprius and lack of resolution of taxa within the B. hydrillae group. However, a majority-rule tree is informative because $94 \%$ of these trees place B. proprius as sister group to the rest of that major grouping; and certain relationships within the B. hydrillae group are supported by a high proportion of trees (Fig. 12).

Fourth, analysis was done with collapsed species groups $(B$. hydrillae group 19 species, and B. adelaidae group of three species), and with characters 3, 14 and 17 highly weighted. It was demonstrated above, that both collapsing of species groups, and weighting of genital characters are valid approaches to analyzing Bagous data sets. Now, lack of resolution persists with respect to the relationship of B. josephi and the B. hydrillae group to the rest of higher Bagous; and, there is lack of resolution among taxa possessing, a dorsal process, B. proprius to B. fritodes (Figs. 13, 14). 


\section{DISCUSSION OF PROBLEMATIC TAXA.}

Genital characters are, in general, quite conservative among Bagous (contrasting with external structure); characters tend not to be lost, but to be more highly modified. Independent derivation of similar structure is much more common, and therefore we base our hypothesis preferentially toward multiple derivation (convergence) and resort to invoking reversals only when no alternative exists. This preference is the reason for using DELTRAN optimization.

1. placement of B. proprius. Among analyses B. proprius is variously positioned as most primitive among species possessing a dorsal process of the median lobe (Fig. 1-4, 6, 10,12), as sister taxon to B. natator (Fig. 13), or closely related to B. subvittatus and B. lewisi (Fig. 8). Lack of derived states for character 16 excludes it from all other species with a dorsal process, however, and the position seems logically intermediate; 30' supports this arrangement (Fig. 2). On the other hand, the median lobe is distinct for other reasons, especially diminutive size, and therefore it is possible that the median setal brush (16) has been lost secondarily due to extreme modification (similarly, $27^{\circ}$ and $30^{\circ}$ could be so reasoned), therefore supporting close relationship to the B. trapae group, represented by B. natator (Fig. 13). At least one other species belongs to the group which B. proprius represents. The species that comprise this group are vastly different in genital structure from other groups (except that there is a dorsal process, char. 14). Therefore, we adopt the hypothesis that certain characters of the median lobe $(16,30)$ are plesiomorphic in the B. proprius group, not secondarily lost.

2. placement of B.josephi and B. hydrillae-groups. In many trees generated (e.g. Figs. 7, 12, 14), PAUP analyses place these as sister taxa as the most parsimonius arrangement (contrasting with Figs. 5, 6, 8-1 1, 13). Previously, we had considered certain characters were homoplastic because development of the pseudo-orifice (37) is entirely different in B. josephi and is probably independently formed. Tibial denticles (119) are lost independently in several independent groups. We are not confident that strict parsimony illustrates the most reasonable arrangement of these taxa. As was postulated in reconstruction of Australian species, we again adopt the position that these two lineages are not sister taxa, and that these character states are indeed homoplastic (Fig. 2).

3. placement of B.apicalis (B. apicalis group) and B. utriculariae (B. humeridens group). Previously (O'Brien \& Askevold, 1992), we did not place these species groups on the same clade. A reconsideration of the relationship of these groups to one another appears to be warranted, in view of added characters and taxa (Fig. 2). PAUP analyses also placed these species as sister taxa as a more parsimonius arrangement (Figs. 5-8, 11-14). The B.apicalis and B. humeridens groups are distinct from one another, but could be considered sister lineages on the basis of several characters: $97^{3}$ (obliterated pronotal median sulcus), $104^{2}$ (side margins of prosternal sulcus acutely raised), $107^{2}$ (humerus oblique, angulately produced), and $125^{3}$ (tarsi linear). Character $104^{2}$ previously supported a larger grouping, but must now be considered homoplastic; $97^{3}, 107^{2}$ and $125^{3}$ were previously considered homoplastic but should now be considered synapomorphic for this group.

4. placement of B. fractus and B. buckinghami. The relationship of these species to others 
possessing a dorsal process is unresolved; there is no support for a distinct relationship between these two taxa nor to any other known taxa, as reflected in reconstructions. In PAUP analyses, these taxa can be variously placed (contrast Figs. 10 vs 11). Our solution is to recognize these as members of separate species groups of undetermined relationship in the genus, except that they belong to the major lineage of taxa possessing a dorsal process (Figs. 1, 2, 13).

5. relationship within the B.bipunctatus group. Analyses produced $100 \%$ concordance among trees generated, and fully resolve the clade including the six included species. Character states are assumed for some missing data (a" states for $B$. subcordatus, $q$ states for B. occultus). Based on preliminary analysis we could confidently assign states for these taxa, for some characters (boldface, Table 1). Character distribution that is most parsimonius requires reversal in characters 37 and 48 . Character 51 is differently formed within members of this group, and we invoke two independent derivations. Based on illustrations of palearctic taxa (Caldara, unpubl. data) and on study of other extralimital taxa (e.g. Africa, Southeast Asia), there are many other species belonging to the lineage represented in the present analysis by these few species. Therefore, we expect that relationships and species group classification will change with future study and be unlike that found here.

\section{SPECIES GROUP CLASSIFICATION.}

Assignment of Japanese Bagous to species groups is based in large part on study of extralimital taxa, including North American, European, Australian and Indian species that we are familiar with or have already monographed. Criteria for recognition are detailed in Methods. Each species group is supported by at least one synapomorphy; presentation is in phylogenetic sequence. Criteria for recognition are detailed in Methods. The species groups are defined by the synapomorphic characters. These synapomorphies and other supporting characters are used in the taxonomic treatment for which this analysis is the basis.

1) B. pygmaeus group. Of Japanese Bagous, only B. minor and B. pygmaeodes fall into this previously recognized group, the $\mathbf{B}$. pygmaeus group. This assignment is supported well by a number of synapomorphies (external characters). The B. pygmaeus group is particularly distinctive in size, elytral scale arrangement, and a number of other derived character states which correlate with this grouping. Unlike most other species groups, there are no genital synapmorphies supporting the group, but this may be because the species are apparently relatively primitive (but the not most primitive) in the genus. We are confident that in subsequent analyses this group will continue to be well-defined. Presently, species of the group are known to occur in Australia, throughout Southeast Asia, India, Japan, and China.

2) B. bipunctatus group. This diverse assemblage of taxa is defined by one distinct character of the internal sac (12') (12 $2^{2}$ in some species), perhaps also 48' (shape of median lobe) with reversal in one group. Character distribution within this group is conflicting and causes lack of resolution of relationships. Many extralimital taxa almost certainly belong to this assemblage, and it is likely that this grouping will be highly modified. A widespread Southeast Asian species, B. vicinus Hustache, possesses these synapomorphies; numerous Palearctic species also appear to belong here, as evidenced by preliminary study of genitalia. Thus the group may become one 
of the most species-rich in the genus and its recognition as a single species group may not be sustained.

3) B. proprius group. This species group is based on the single described species. Species of this group are distinctive in structure of the median lobe $\left(16^{0}, 27^{\circ}\right.$ and $\left.42^{1}\right)$, quite unlike most other Bagous. Among Bagous with a dorsal process (14), these species are the only ones lacking a setal brush $\left(16^{\circ}\right)$ and truncate basal margin $\left(27^{0}\right.$, a reversal); its phylogenetic position in the genus therefore seems quite certain. Presently, two species of the group are known to occur in Southeast Asia, India, and Japan, with the second species undescribed.

4) B. buckinghamithisouppecies group is based on the single described species. It is distinctive in shape of the median lobe (which is constricted and slightly asymmetrical), female sternite VIII (lacks setae, arms narrow) and gonocoxae (sinuate and lack stylus), quite unlike any Bagous known to us at this time (these characters are not established in the phylogenetic data set). The group is presently known only from Japan, but like other species groups certainly will have extralimital members.

5) B. fractus group. Though the only presently included species is from Japan, we presume that other species belong in the group. A number of non-Japanese species possessing a dorsal process have a general facies of the median lobe that is similar to the Japanese species $B$. fructus. We do not define the group with synapomorphies at this time. The acute lateral margin behind the dorsal process, median lobe apically asymmetrical (36), prominently bicarinate ventral surface of the median lobe $\left(30^{2}\right)$ and apically fused arms of sternum VIII of females $\left(58^{1}\right)$ may be such characters. These character states are possessed by extralimital species. Because B. fractus is unique among Japanese species, and because there seem to be closely related extralimital taxa, we erect this group for B. fractus alone at this time.

6) B. rotundatusgroup. This species group is based on this single species. It is distinctive in body shape (very rotund) and structure of the median lobe (44), and therefore is quite unlike any Bagous known to us. Though presently the only included species is from Japan, we presume that other species belong in the group. Tentatively, we define the group with the genital synapomorphies of $38^{2}$ (median lobe apodemes short, apically sinuate) and 44 (swollen lateral margin behind dorsal process); additionally, the overall rotund body could be added but this character is not presently in the phylogenetic data set. The species possesses denticles inside the dorsal process (17), which groups this and the B. transversus- and B.fritodes-groups.

7) B. transversus group. Several species from North America, India, and now also Japan, share a structure of the median lobe that is quite distinctive $(19,45)$. The only species in this group that is already described is the North American B. transversus, which is common in collections. At least one undescribed Indian species also belongs to this group. Additional characters (17 and 34) are also distinctive, but are shared by the 5. rotundatus- and B. fritodesgroups. We are confident that this species group is well-founded and that it will continue to be supported in future analyses.

8) $B$. frit group. The European species, $B$. frit, and the Japanese species $B$. fritodes, are 
distinctive in structure of the median lobe (52). Other distinctive characters define the group but are not uniquely derived: character 20 is also shared by the B. addaidaegroup; characters 32 and 36 occur in members of a number of other species groups; character 34 is shared by the B. transversus group, and 17 by the B. transversus and B. rotundatus groups. Presently, only two species of the group are known, in Europe and Japan; while others may be found to belong to the group, we are confident that the group is well-founded and will be supported in future analyses.

9) Species of uncertain taxonomic position. Three species (B. lewisi, B. tuberculosus, B. subvittatus), which are known only from female specimens, are left unassigned to species group. While female genital characters in the genus are distinctive, these species lack the distinctive characters that may indicate probable group affinity. External characters are entirely equivocal, because these species share characters with any of several other species groups and each other. These taxa are left unrooted in the manual construction (Fig. 1) and are deleted from phylogenetic consideration in PAUP analyses, except for analysis of external characters only (Fig. 8).

\section{ACKNOWLEDGMENTS.}

We would like to thank the curators (named in Materials) for loan of specimens on which this study is based. We owe Drs. Robert S. Anderson, Horace R. Burke and James Pakaluk many thanks for their review, helpful comments, and criticism of this manuscript.

Research leading to this publication was supported in part by a grant \#58-43YK-9-0011 ARS (Agricultural Research Service, U.S.D.A.), and a grant FLAX 850006 from C.S.R.S. (Cooperative State Research Service, U.S.D.A.). Partial support was provided by a grant from C.S.R.S., U.S.D.A. to Florida A \& M University, which provided funds for the MacIntosh computer. Research on the part of I.S. Askevold was supported in part also by a Natural Sciences and Engineering Research Council of Canada Post-Doctoral Fellowship.

\section{REFERENCES CITED.}

Anderson, R.S. 198'7. Systematics, phylogeny and biogeography of New World weevils traditionally of the tribe Cleonini (Coleoptera: Curculionidae); Cleoninae). Quaestiones Entomologicae 23:43 1-709.

Askevold, I.S. 1988. The genus Neohaemonia Székessy in North America (Coleoptera: Chrysomelidae: Donaciine): systematics, reconstructed phylogeny, and geographic history. Transactions of the American Entomological Society 113:360-430.

Askevold, I.S. 1990. Reconstructed phylogeny and reclassification of the genera of Donaciinae (Coleoptera: Chrysomelidae). Quaestiones Entomologicae 26:601-664.

Askevold, I.S. 1991. Classification, reconstructed phylogeny and geographic history of the New World members of Plateumaris Thomson, 1859 (Coleoptera: Chrysomelidae: Donaciinae). Memoirs of the Canadian Entomological Society, 157:5-175.

Askevold, I.S. and C.W. O'Brien. 1994. DELTA, an invaluable computer program for generation 
of taxonomic monographs. Annals of the Entomological Society of America. 87:1-16.

Dallwitz, M.J. and T.A. Paine, 1986. User's Guide to the DELTA System. A General System for Processing Taxonomic Descriptions, 3rd Ed. CSIRO Division of Entomology Report No. 13.

Farris, J.S. 1969. A successive weighting approximations approach to character analysis. Systematic Zoology 18:374-385.

Hennig, W. 1965. Phylogenetic systematics. Annual Review of Entomology 10:97-1 16.

Hennig, W. 1966. Phylogenetic systematics. University of Illinois Press. ii +263 pp.

Marsall, S.A. 1987. Systematics of Bitheca, a new genus of New World Sphaeroceridae (Diptera). Systematic Entomology 12:355-380.

O'Brien, C.W. and I.S. Askevold, 1992. Systematics and evolution of weevils of the genus Bagous Germar (Coleoptera: Curculionidae), I. The species of Australia. Transactions of the American Entomological Society 118:331-452.

O'Brien, C.W., K. Morimoto and I.S. Askevold, 1994. Systematics and evolution of weevils of the genus Bagous Germar (Coleoptera: Curculiqnidae) II. Taxonomic treatment of the species of Japan. Esakia 38:1-73.

Partridge, T.R., M.J. Dallwitz and L. Watson, 1988. A Primer for the DELTA System on MSDOS and VMS, 2nd Ed. CSIRO Division of Entomology Report No. 38.

Sharkey, M.J. 1989. A hypothesis-independent method of character weighting for cladistic analysis. Cladistics 5:63-86.

Swofford, D.L. 1993. PAUP: Phylogenetic analysis using parsimony, Version 3.1.1. Computer program distributed by the Illinois Natural History Survey, Champaign, Illinois.

Wharton, R.A., S.R. Shaw, M.J. Sharkey, D.B. Wahl, J.B. Woolley, J.B. Whitfield, P.M. Marsh and W. Johnson. 1992. Phylogeny of the subfamilies of the family Braconidae (Hymenoptera: Ichneumonoidea): a reassessment. Cladistics 8:199-235.

Wiley, E.O. 1981. Phylogenetics: the theory and practise of phylogenetic systematics. John Wiley \& Sons $\mathrm{xv}+439 \mathrm{pp}$.

Wiley, E.O., D. Siegel-Causey, D.R. Brooks, V.A. Funk. 1991. The compleat cladist. A primer of phylogenetic procedures. University of Kansas Museum of Natural History, Special Publications No. 19 ix +158 pp.

Yeates, D. 1992. Why remove autapomorphies? Cladistics 8:387-389. 


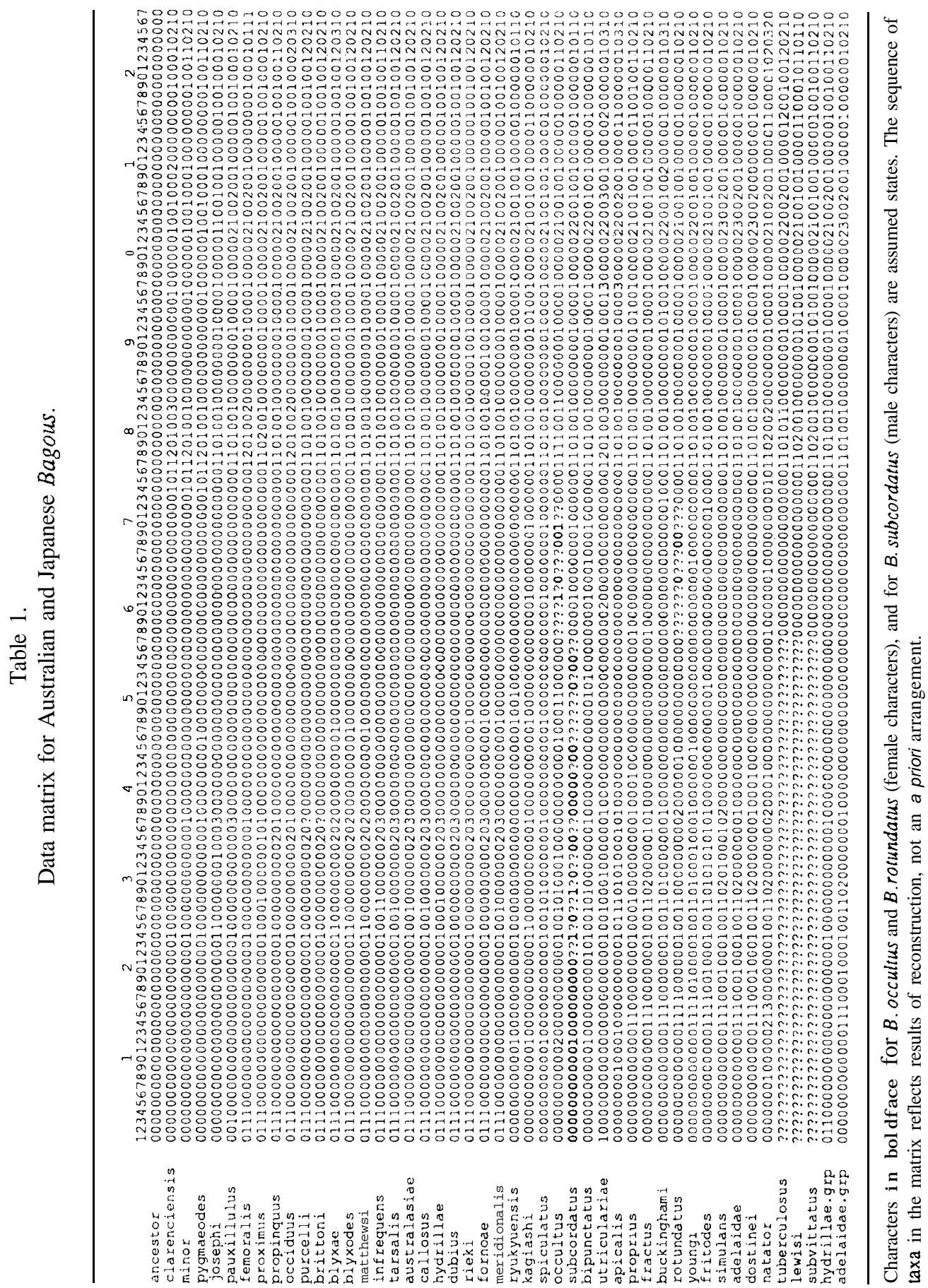




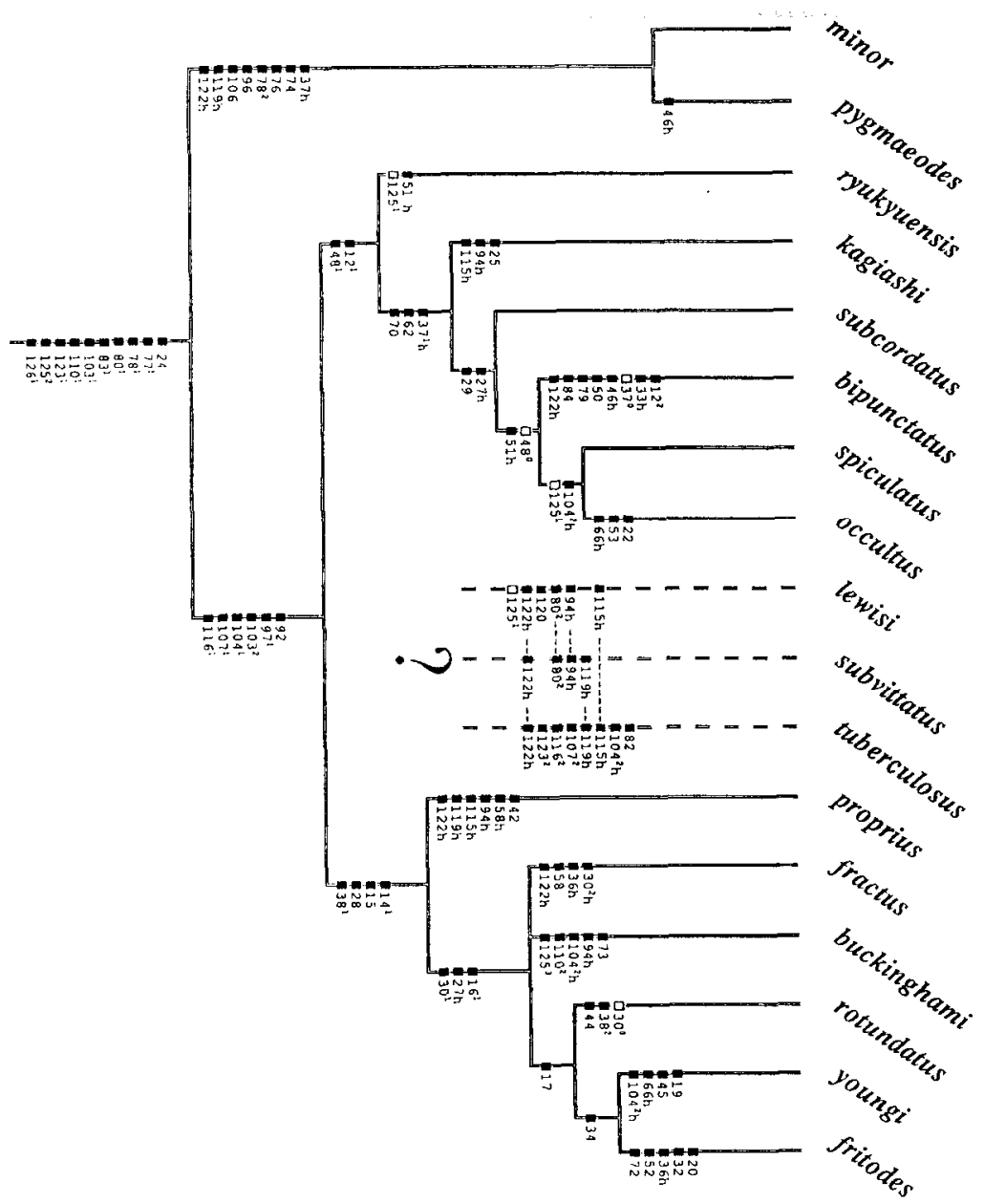

Fig. 1. Reconstructed relative relationships of Japanese Bagous, by manual reconstruction. $\mathrm{h}=$ homoplastic occurrences of derived character states; $\mathbf{-}=$ apomorphic character state; $\square=$ plesiomorphic character state achieved by reversal. Superscript values refer to the derived state; apomorphic state 1 is assumed unless otherwise indicated. Interrupted lineages indicate taxa of equivocal position and not rooted to tree. 


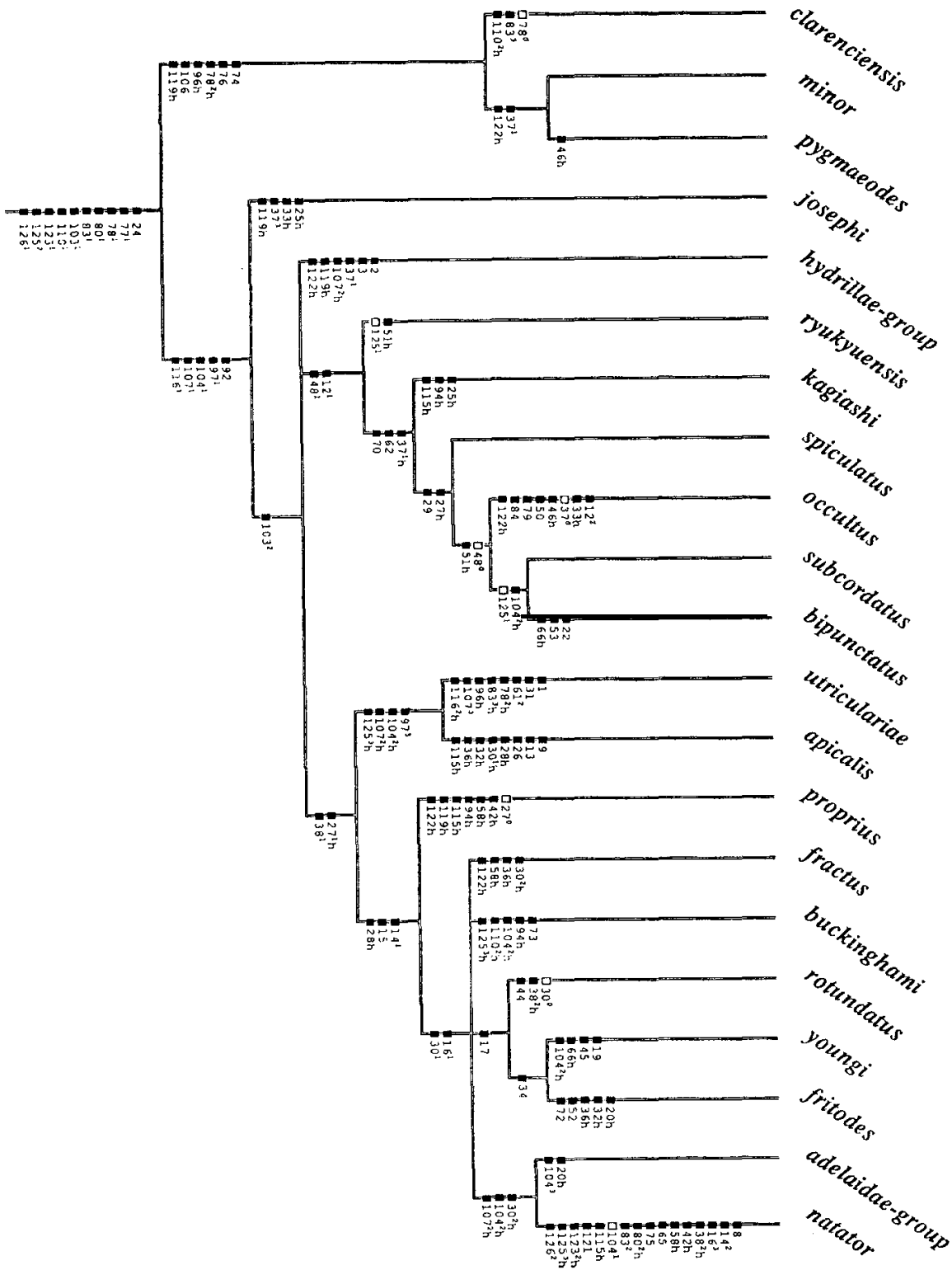

Fig. 2. Reconstructed relative relationships Japanese Bagous, by PAUP reconstruction: strict consensus tree of 7 equally parsimonius trees generated by heuristic and branch-and-bound search, with characters unweighted. The species B. tuberculosus, B. lewisi and B. subvittatus are not included. 

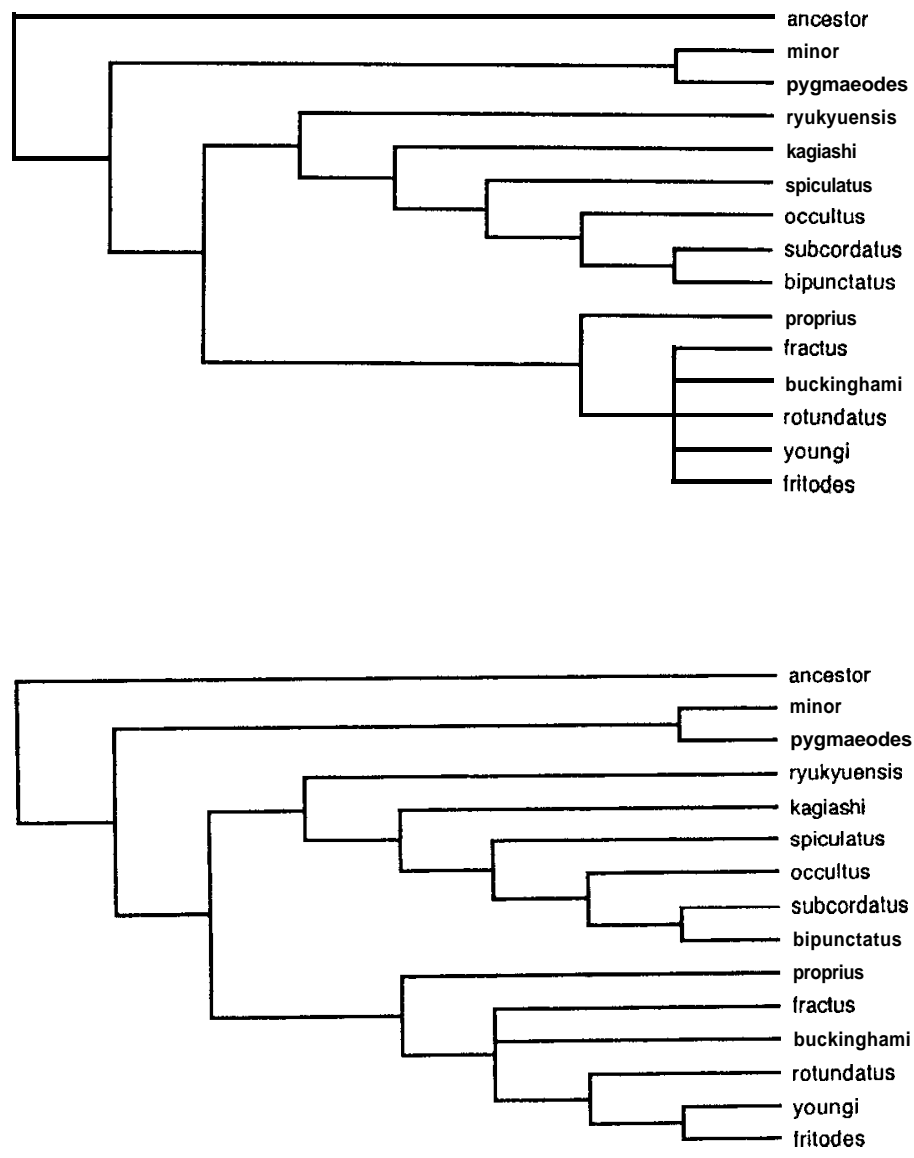

Figs. 3 \& 4 . Reconstructed relative relationships Japanese Bagous, by PAUP reconstruction generated by heuristic and branch-and-bound searches. The species $B$. tuberculosus, $B$. lewisi and $B$. subvittatus are not included. 3, Using unweighted characters: strict consensus of 7 equally parsimonius trees. 4, using weighted characters: strict consensus tree of 3 equally parsimonius trees generated by heuristic and branch-and-bound search. The Japanese species B. tuberculosus, B. lewisi and B. subvittatus are not included. 


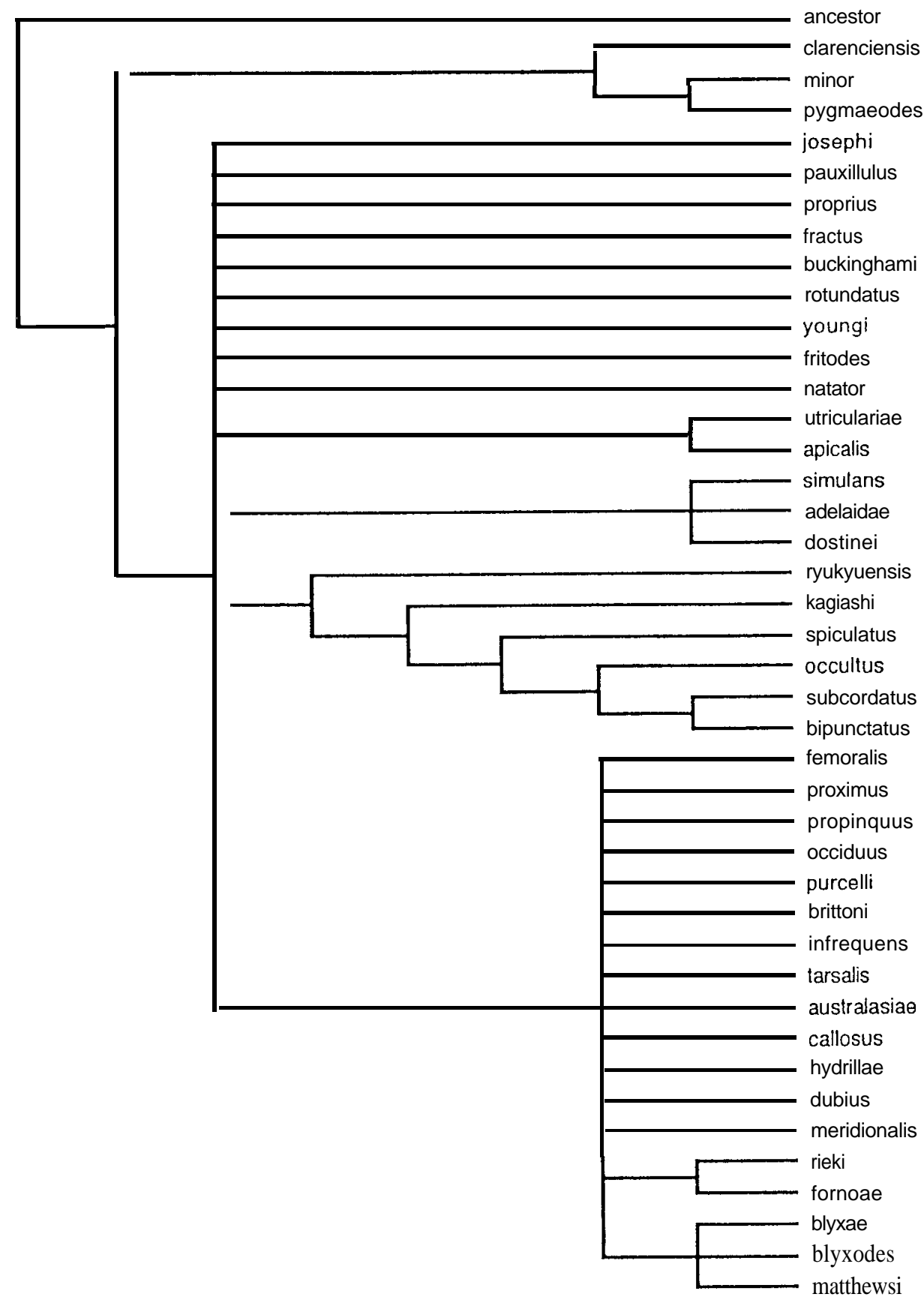

Fig. 5. Analysis of Japanese and Australian Bagous, by PAUP reconstruction, using unweighted characters: strict consensus tree. The Japanese species B. tuberculosus, B. lewisi and $B$. subvittatus are not included. 


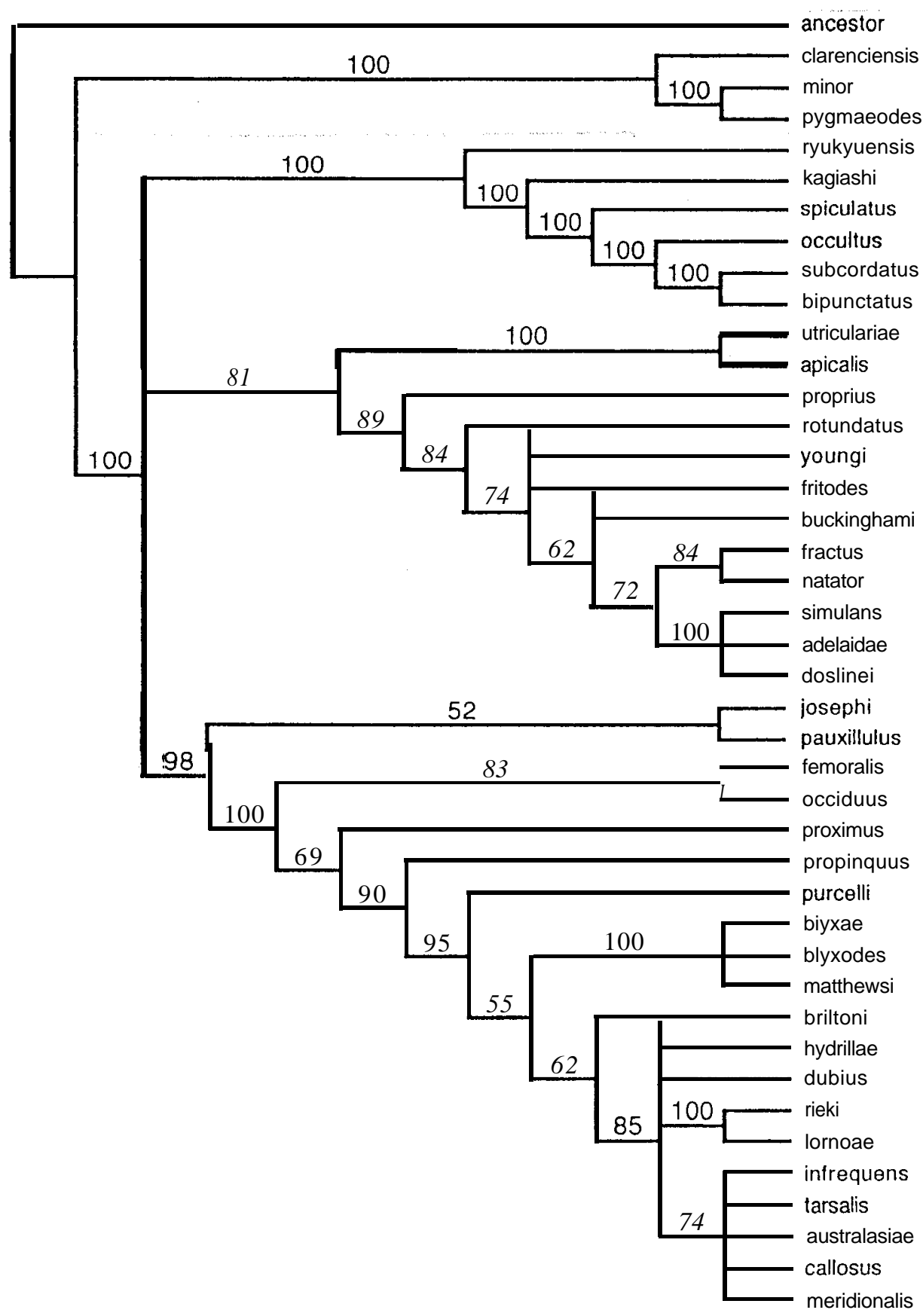

Fig. 6. Analysis of Japanese and Australian Bagous, by PAUP reconstruction, using unweighted characters: $50 \%$ majority-rule consensus tree. The Japanese species B. tuberculosus, B. lewisi and B. subvittatus are not included. 


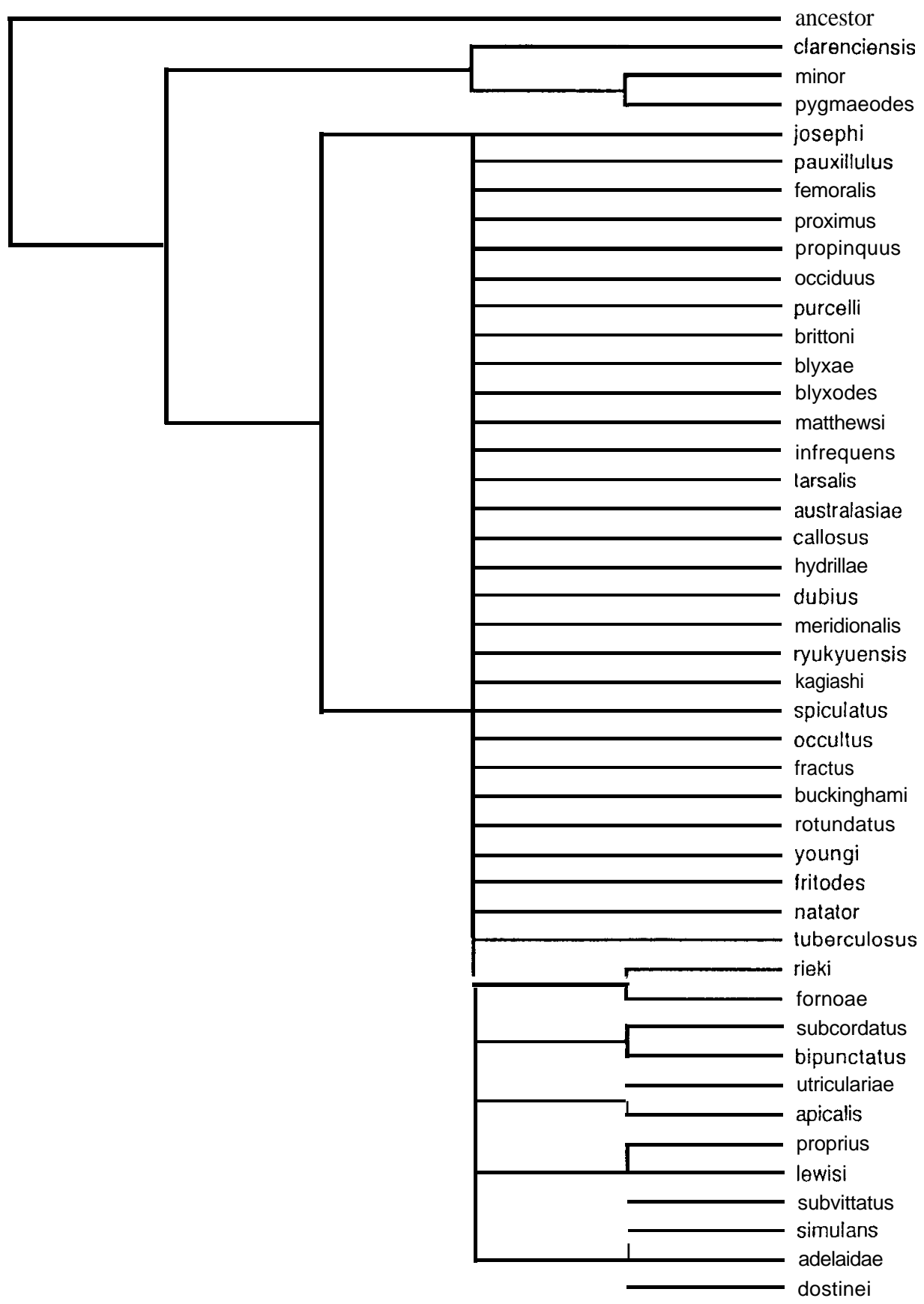

Fig. 7. Analysis of Japanese and Australian Bagous, by PAUP reconstruction, using unweighted, external characters only: strict consensus tree. The Japanese species B. tuberculosus, B. lewisi and B. subvittatus are included in this analysis. 


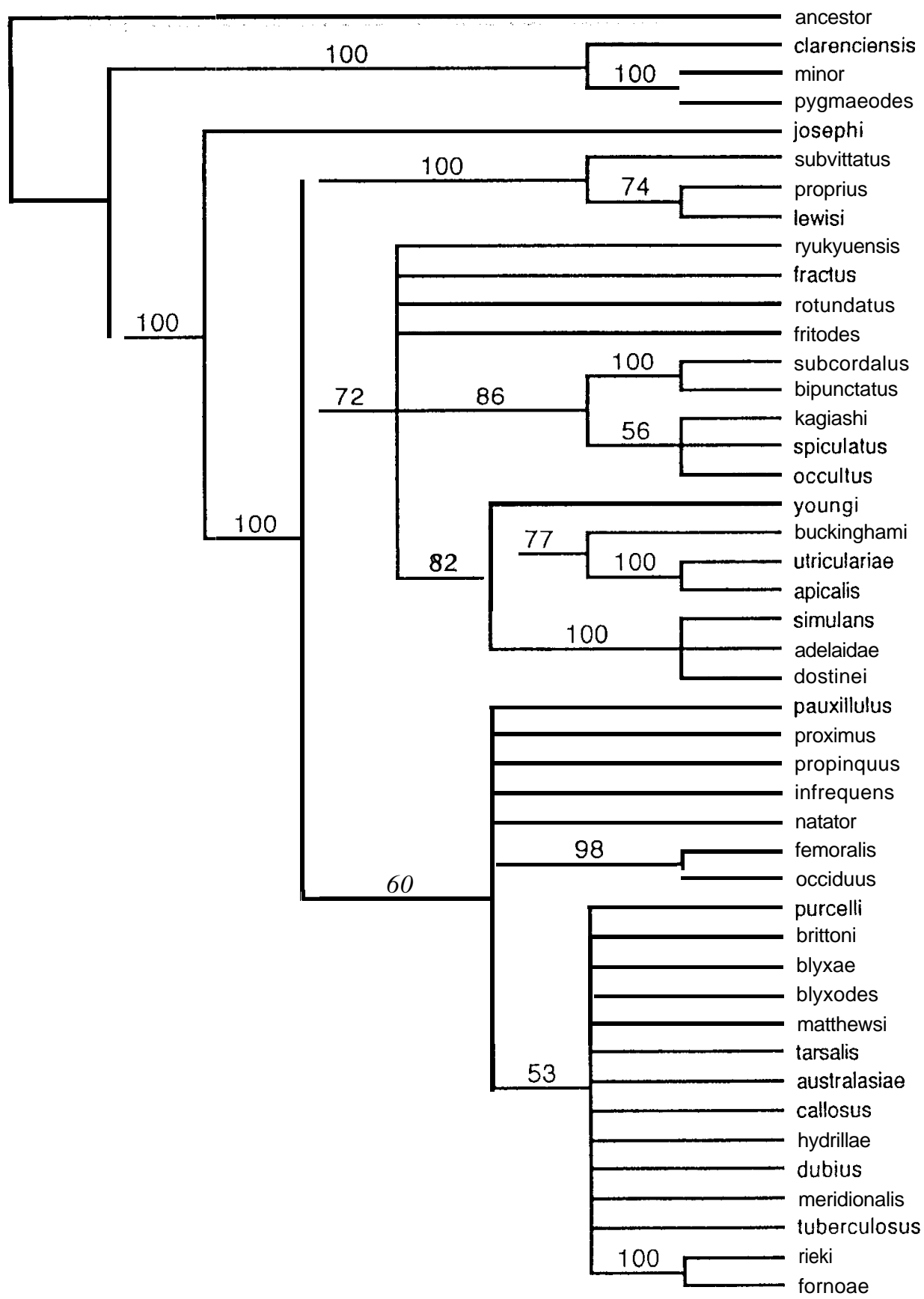

Fig. 8. Analysis of Japanese and Australian Bagous, by PAUP reconstruction, using unweighted, external characters only: $50 \%$ majority-rule consensus tree. The Japanese species B. tuberculosus, B. lewisi and B. subvittatus are included in this analysis. 


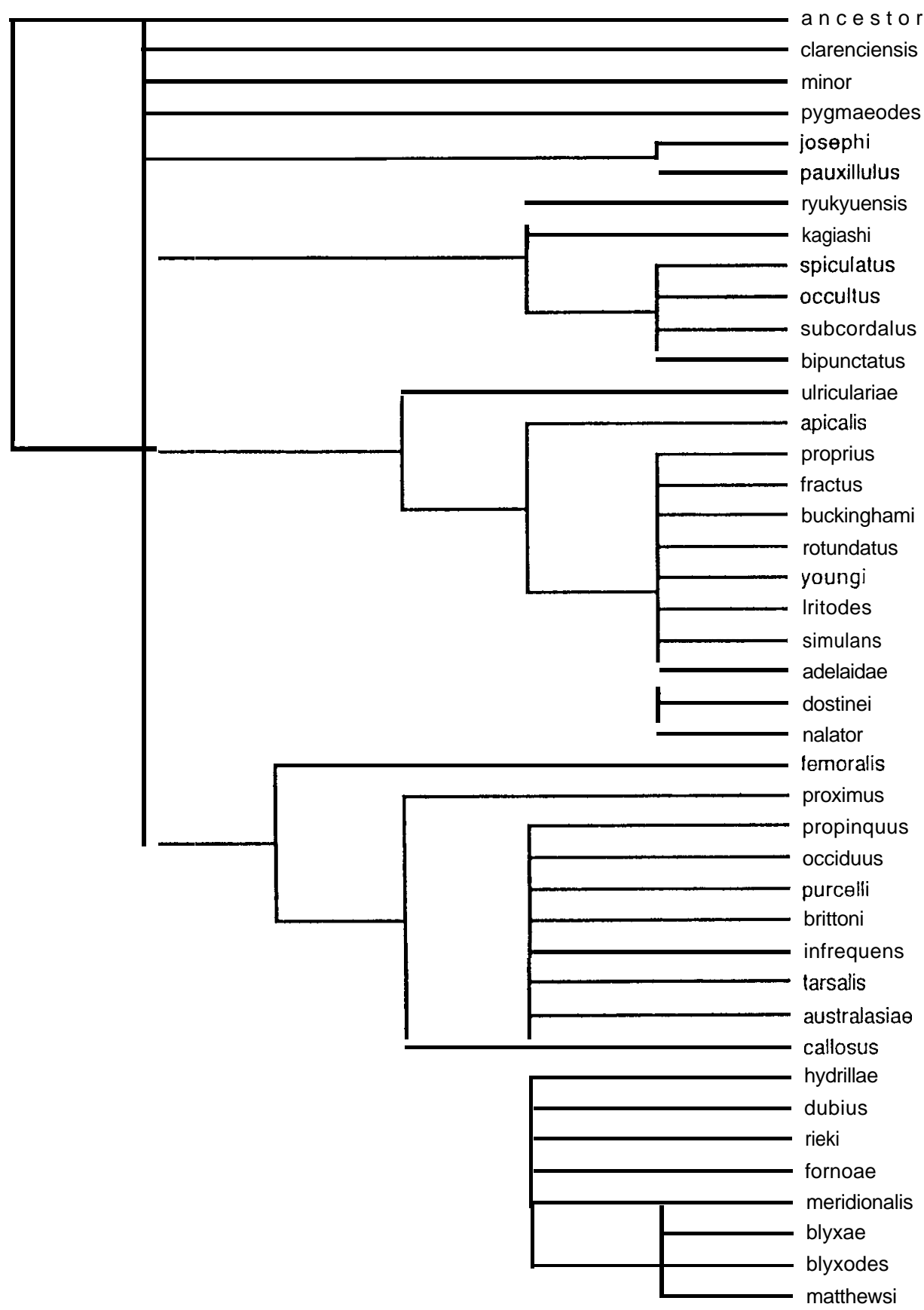

Fig. 9. Analysis of Japanese and Australian Bagous, by PAUP reconstruction, using unweighted, genital characters only: strict consensus tree. The Japanese species B. tuberculosus, B.lewisi and B. subvittatus are not included. 


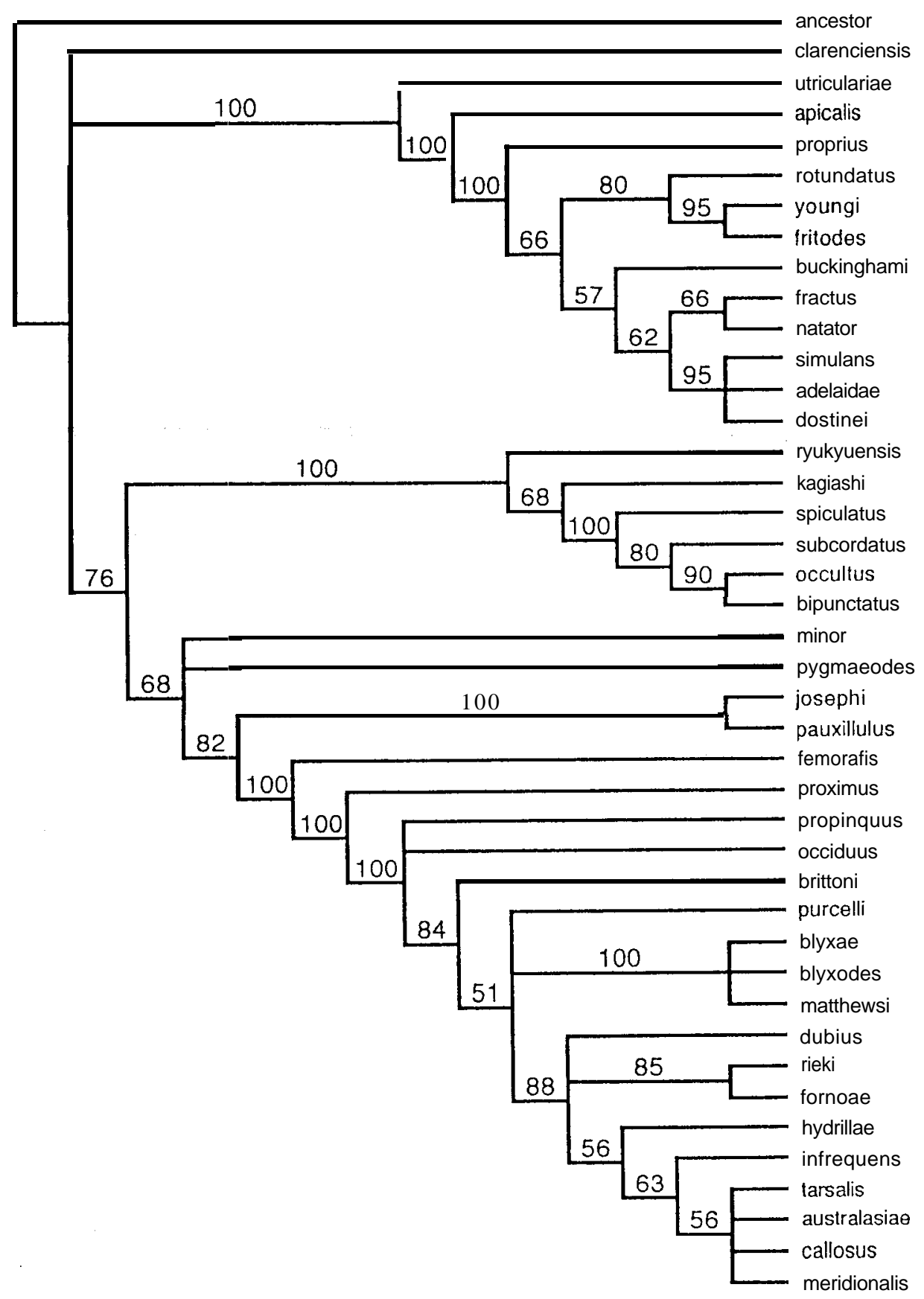

Fig. 10. Analysis of Japanese and Australian Bagous, by PAUP reconstruction, using unweighted, genital characters only: $50 \%$ majority-rule consensus tree. The Japanese species $B$. tuberculosus, B. lewisi and B. subvittatus are not included. 


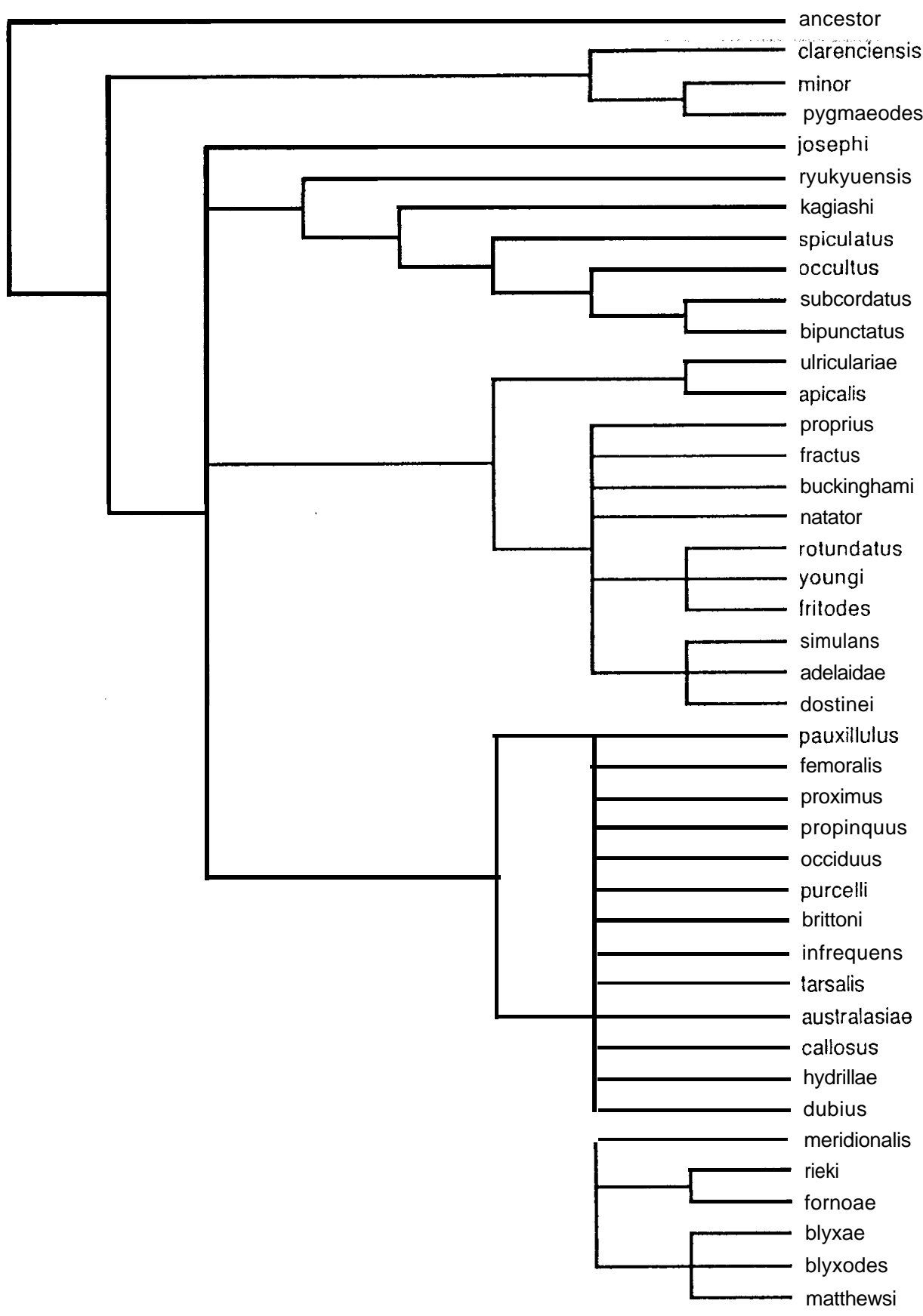

Fig. 11. Analysis of Japanese and Australian Bagous, by PAUP reconstruction, using all characters, with 3,14 and 17 weighted: strict consensus tree. The Japanese species B. tuberculosus, B. lewisi and B. subvittatus are not included. 


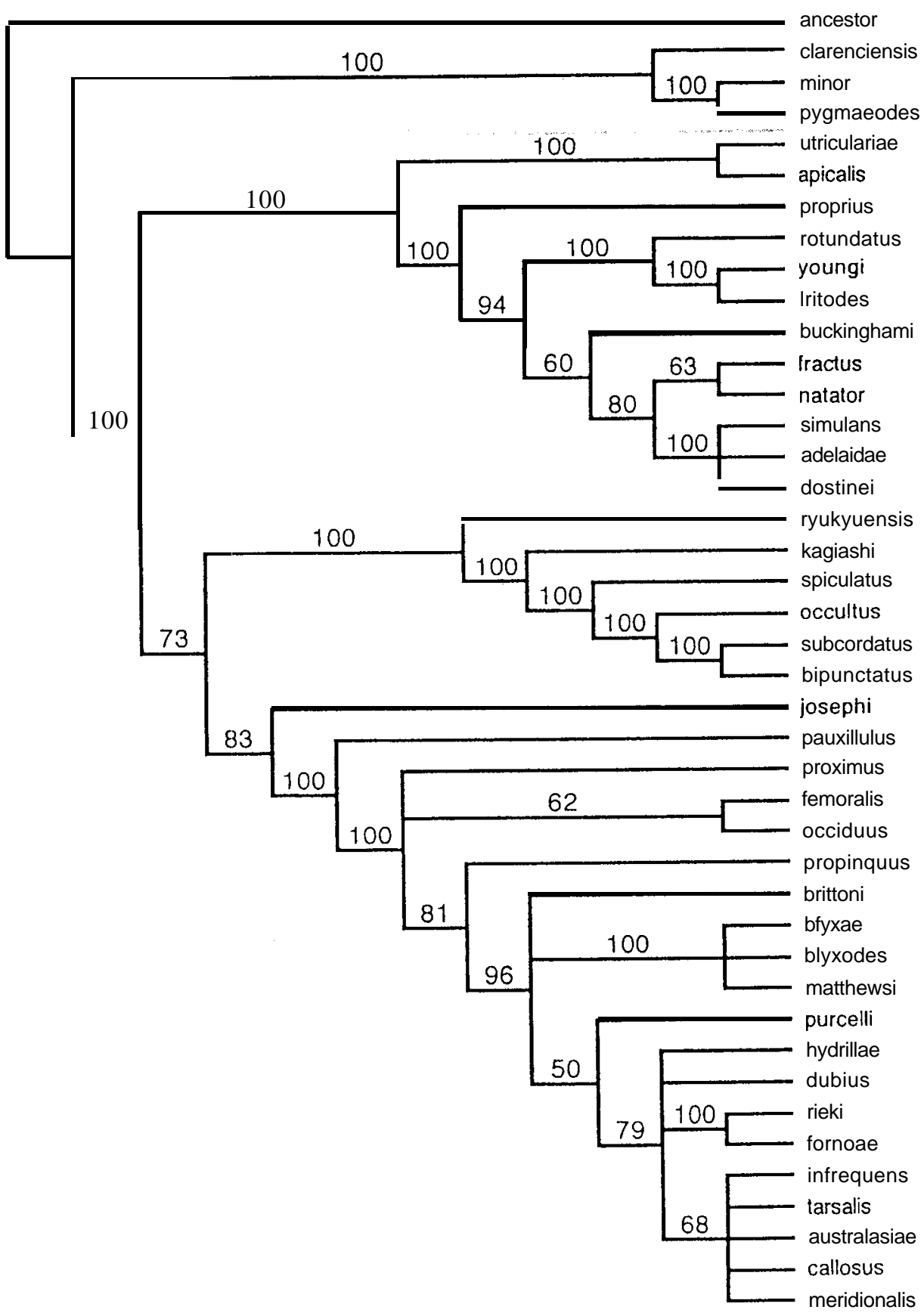

Fig. 12. Analysis of Japanese and Australian Bagous, by PAUP reconstruction, using all characters, with 3,14 and 17 weighted: $50 \%$ majority-rule consensus tree. The Japanese species B. tuberculosus, B. lewisi and B. subvittatus are not included. 


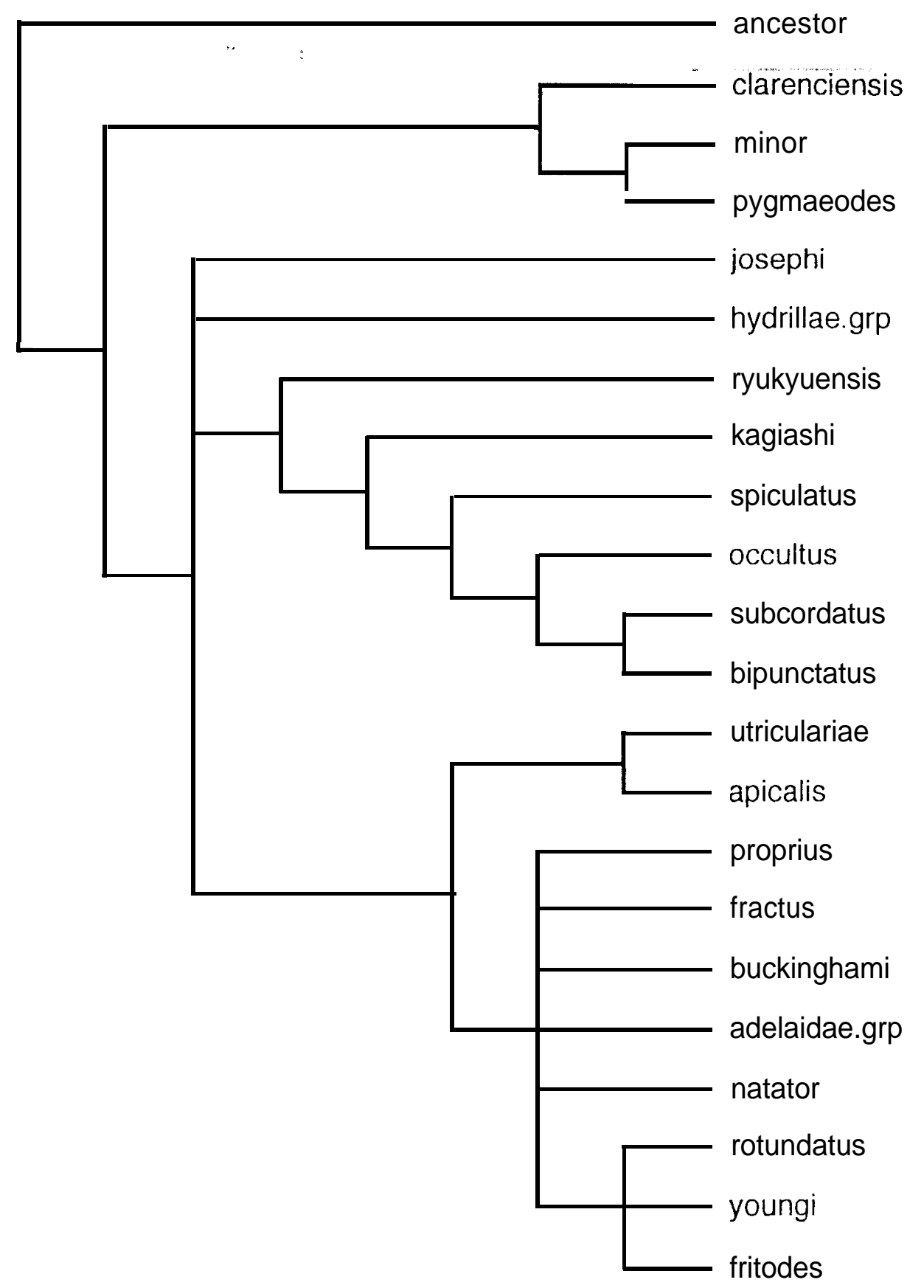

Fig. 13. Analysis of Japanese and Australian Bagous with species groups collapsed to single lineages, by PAUP reconstruction, using all characters, with 3, 14 and 17 weighted: strict consensus tree. The species B. tuberculosus, B.lewisi and B. subvittatus are not included. 


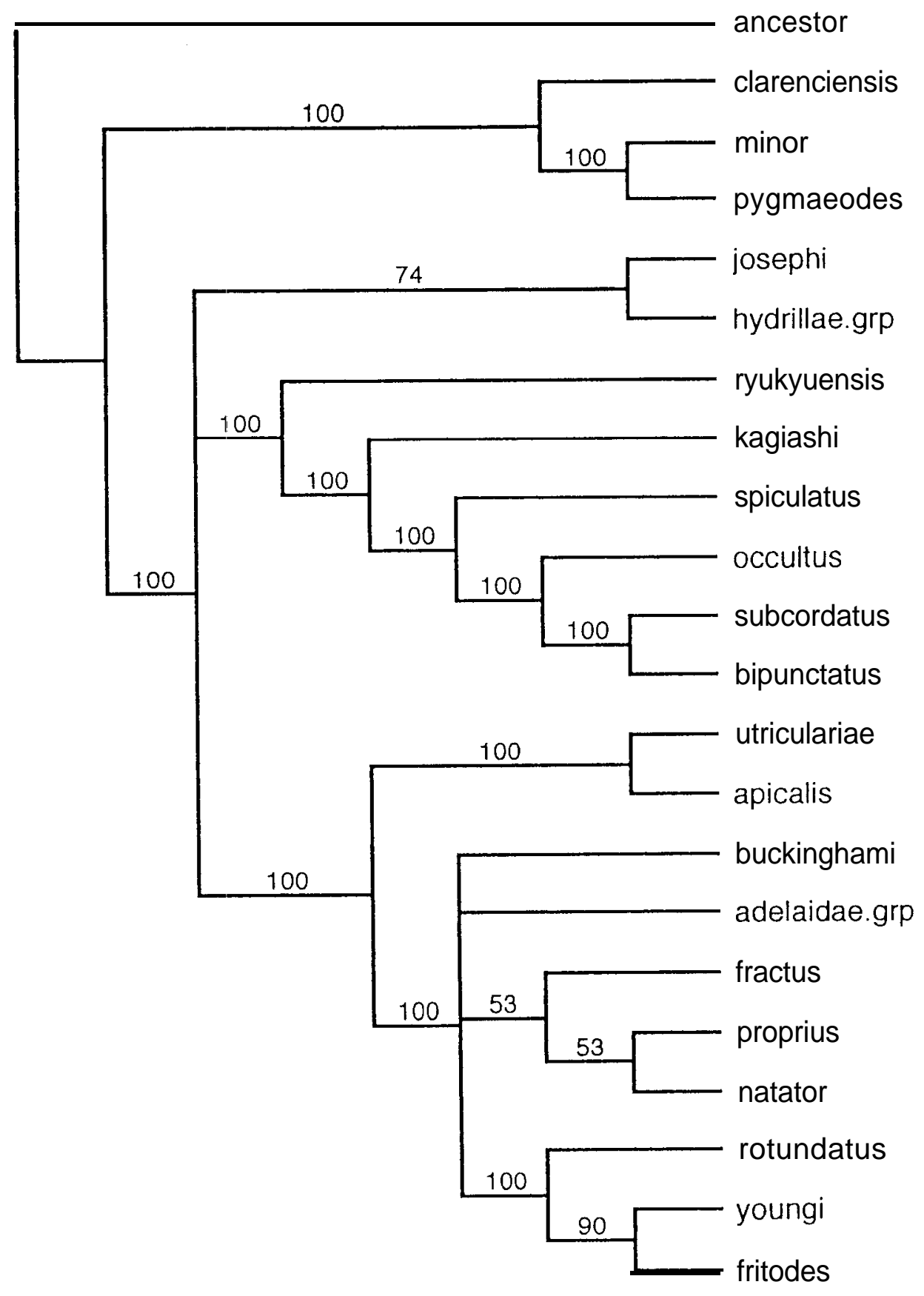

Fig. 14. Analysis of Japanese and Australian Bagous with species groups collapsed to single lineages, by PAUP reconstruction, with characters 3, 14 and 17 weighted: 50\% majority-rule consensus tree. The species B. tuberculosus, B. lewisi and B. subvittatus are not included. 